Georgia State University

ScholarWorks @ Georgia State University

Computer Information Systems Faculty

Publications

Department of Computer Information Systems

2009

\title{
Offshore Information Systems Project Success: The Role of Social Embeddedness and Cultural Characteristics
}

\author{
Arun Rai \\ Georgia State University, arunrai@gsu.edu \\ Likoebe M. Maruping \\ University of Arkansas, Fayetteville, Imaruping@walton.uark.edu \\ Viswanath Venkatesh \\ University of Arkansas, Fayetteville, vvenkatesh@vvenkatesh.us
}

Follow this and additional works at: https://scholarworks.gsu.edu/cis_facpub

Part of the Management Information Systems Commons

\section{Recommended Citation}

Rai, A., Maruping, L., and Venkatesh, V., Offshore Information Systems Project Success: The Role of Social Embeddedness and Cultural Characteristics, MIS Quarterly, 33 (3), 2009, 617-641. http://misq.org/ offshore-information-systems-project-success-the-role-of-social-embeddedness.html.

This Article is brought to you for free and open access by the Department of Computer Information Systems at ScholarWorks @ Georgia State University. It has been accepted for inclusion in Computer Information Systems Faculty Publications by an authorized administrator of ScholarWorks @ Georgia State University. For more information, please contact scholarworks@gsu.edu. 


\section{Offshore Information Systems Project Success: THE ROLE OF SOCIAL EMBEDDEDNESS AND CULTURAL CHARACTERISTICS ${ }^{1}$}

By: Arun Rai

Robinson College of Business

Georgia State University

Atlanta, GA 30303

U.S.A.

arunrai@gsu.edu

Likoebe M. Maruping

Walton College of Business

University of Arkansas

Fayetteville, AR 72701

U.S.A.

Imaruping@walton.uark.edu

Viswanath Venkatesh

Walton College of Business

University of Arkansas

Fayetteville, AR 72701

U.S.A.

vvenkatesh@vvenkatesh.us

\begin{abstract}
Agency theory has served as a key basis for identifying drivers of offshore information system project success. Consequently, the role of relational factors in driving project success has been overlooked in this literature. In this paper, we address this gap by integrating the social embeddedness
\end{abstract}

${ }^{1}$ This paper was recommended for acceptance by Associate Guest Editor Peter Seddon.

Note: The appendices for this paper are available online at http://misq.org/ archivist/appendices//RaiMarupingAppendices.pdf. perspective and the culture literature to theorize how and why relational factors affect the success of offshore IS projects that are strategic in nature. We identify organizational and interpersonal cultural differences as critical success factors in this context. Using data from a longitudinal field study of 155 offshore IS projects managed by 22 project leaders, we found evidence of a relationship between hypothesized relational factors and two measures of offshore IS project success-namely, project cost overruns and client satisfaction-over and above the effects of project characteristics and agency factors. Specifically, we found that information exchange, joint problem solving, and trust reduce project cost overruns and improve client satisfaction. We also found a relationship between cultural differences at the organizational and team level, and offshore IS project success. The model explained 40 percent and 41 percent of the variance in project cost overruns and client satisfaction, respectively, for projects with a client representative. For projects with no client representative, the model explained 35 percent and 37 percent of the variance in project cost overruns and client satisfaction, respectively. Collectively, the results have important theoretical and practical implications for how clientvendor relationships should be managed when partnering with offshore firms and designing offshore IS project teams.

Keywords: Offshoring, social embeddedness, project management, agency theory, culture, multilevel

\section{Introduction}

The offshoring of information systems development projects, which is the focus of our investigation, involves a client 
organization's outsourcing of a development project to a vendor located in another country (Carmel and Agarwal 2002; Gopal et al. 2002). China and India, two of the most populous countries with a large and expanding base of information technology human capital, have emerged as the largest centers for offshored IT work (Friedman 2005). In particular, offshoring of IS projects to these countries has gained momentum as companies strive to offset the IT costs associated with developing not only routine, transaction-based systems, but also complex, customized strategic systems (Carmel and Agarwal 2002). The momentum in offshoring has resulted in an annual growth rate of 20 percent, with estimates of U.S.\$17.2 billion worth of IS projects offshored to India (Thibodeau 2005). India's offshoring industry alone is projected to reach U.S.\$60 billion by 2010 (Ribeiro 2005). These offshoring decisions have been triggered not only by lower labor costs but also by Six Sigma quality control systems and process capabilities, such as Level-5 Capability Maturity Model (CMM) certifications, of leading offshore vendors (Kaiser and Hawk 2004).

While there are potential benefits in offshoring IS development, there are significant challenges associated with realizing them. Despite the employment of practices prescribed by the agency theory perspective to promote success in offshore IS development projects, several companies, such as Life Time Fitness, have reported significant overruns in budget and schedule. Postmortems of such failed projects point to relational factors, such as communication challenges and misunderstandings due to cultural differences, as key reasons for cost escalation and client dissatisfaction (Bertch 2003; Krishna et al. 2004; Sahay et al. 2003). The implications of such challenges are especially significant for strategic projects that are idiosyncratic in nature and complex in scope, given that such projects require the integration of tacit knowledge across the client and vendor firm (Nicholson and Sahay 2004). Relational factors that characterize the nature of the interaction in the exchange process between two parties can have a profound influence on the transmission and integration of such knowledge (Uzzi 1997), which is critical for offshore IS project success. In light of the critical nature of these projects and the problems being encountered, our research objective is to understand the role of relational factors in influencing strategic offshore IS project success.

From a theoretical perspective, some progress has been made on how to manage offshore IS projects, primarily by drawing on the IS outsourcing literature that has evaluated agencyrelated factors, including formal and psychological contracts, and project characteristics (e.g., Banerjee and Duflo 2000; Choudhury and Sabherwal 2003; Gopal et al. 2003; Koh et al. 2004; Nidumolu and Subramani 2003). This literature pro- vides strong evidence that formal controls, incentives, and project characteristics influence the success of offshore IS projects. However, agency theory is constrained in its explanatory power. It limits attention to the motivations for selfinterested behaviors and to formal mechanisms that safeguard against them (Dyer and Singh 1998; Uzzi 1997), and does not directly address the relational aspects of interfirm interactions. Offshore IS projects require that teams effectively collaborate to integrate specialized and tacit knowledge distributed across firm and cultural boundaries (Faraj and Sproull 2000; Guinan et al. 1998; Kirsch 1997; Koh et al. 2004; Nicholson and Sahay 2004). In such settings, the social embeddedness perspective suggests that the structure of the exchange relationship has a significant impact on economic action (Granovetter 1985; Uzzi 1997). Its core argument is that embedded relations, in contrast to atomistic arms-length exchanges, exhibit shared norms and values, reduce the need for monitoring and control, and facilitate the transfer of information and integration of specialized knowledge and capabilities. The economic implication of such embeddedness is expected to be especially important in a context such as strategic IS project development, where tacit knowledge has to be integrated and idiosyncratic problems have to be addressed. Thus, the social embeddedness perspective is an appropriate lens through which to understand the role of relational factors in offshore IS project success.

To add to our understanding on how to manage offshore IS projects, we follow Johns' (2006) recommendation to contextualize theory by evaluating the impact of properties of social structure in the offshore IS project context. We evaluate how espoused cultural characteristics of the IS project leader influence success. Further, we contextualize the social embeddedness perspective ${ }^{2}$ to the IS offshore context and apply a cultural differences framing to evaluate shared values and norms in projects with client representation. We assess these differences at two levels: (1) between the cultural norms for work practices (Hofstede et al. 1990) of the client and vendor firm; and (2) between the espoused cultural values of two key individuals (e.g., Srite and Karahanna 2006) in a team: the project leader and the client representative. We empirically test our hypotheses using a sample of 155 strategic IS projects that were offshored by U.S. firms to a major Indian vendor with Level-5 CMMi certification. Our study contributes to the IS offshoring literature by augmenting explanations of agency and project characteristics for offshore IS project success, with factors related to social structure and cultural differences.

\footnotetext{
${ }^{2}$ The terms social embeddedness and relational exchange have been used interchangeably in the literature.
} 
Theoretical Framework and Hypotheses Development

We first set the stage for our theory development by specifying the type of project that is of interest to us. Our focus is on strategic projects that are inherently idiosyncratic and require the integration of tacit knowledge and business domain expertise from the client with the technical development expertise of the vendor. The key constructs that we consider in our theorizing about offshore IS project success are mapped to the social embeddedness perspective and summarized in Table 1. As shown in Table 1, the project characteristics and agency-related factors that are well established in the literature are specified as control variables. We proceed to develop our logic for a social embeddedness perspective for offshore IS projects, contextualize the relational exchange mechanisms for the development of offshore projects, and derive specific hypotheses for each of these mechanisms. Following these hypotheses, we augment the role of relational mechanisms with the role of project leader cultural values and shared values and norms. We suggest that the cultural characteristics of the project leader can have a significant impact on project success. We also argue that cultural differences operate at two levels - at the macro-level between the firms and at the micro-level between the client representative and IS project leader-with cultural differences having an impact on offshore IS project success.

\section{Types of Offshore IS Projects: A Focus on Strategic Projects}

IS project offshoring involves a client organization outsourcing all or part of IS project work to a vendor in a different country. The contracting firms can engage in offshore IS projects for cost-only or broader strategic reasons (Carmel and Agarwal 2002). To pursue cost efficiencies, a firm can outsource noncore IS projects, such as those for routine transactions (Lacity and Willcocks 1998; Lee et al. 2004), for which offshore vendors likely have developed reusable modules and components. In contrast, the client firm can engage in offshore arrangements to develop complex end-toend systems or new IT products for its business needs (Carmel and Agarwal 2002). For such systems, the vendor has to devote resources to understand the client's business domain knowledge and its differentiated requirements in contrast to solutions that entail the repackaging of previously developed and tested modules. As Sedigh-Ali et al. (2001) note, the risks and cost structures associated with systems that are custom developed are different from systems that are developed using commercial off-the-shelf components. We focus our attention on such customized IT solutions that are strategic in nature for the client firm, as their successful development is especially sensitive to the integration of specialized knowledge that is distributed across the onshore client and offshore vendor and, therefore, across cultural boundaries.

\section{Social Embeddedness and Offshore IS Project Success}

In the offshoring context, the onshore client solicits the services of the offshore vendor to manage an IS project and thereby establishes a cross-cultural exchange relationship for the project. We suggest that an agent-theoretic perspective does not fully capture the key elements of social structure and the cultural context of the exchange relationship in which these offshored IS development projects occur. To elaborate, Jensen and Meckling (1976) define an agency relationship as "a contract under which one or more persons (the principal(s)) engage another person (the agent) to perform some service on their behalf which involves delegating some decision-making authority to the agent" (p. 308). Based on this definition, agency theory frames the interaction within the offshored project as an arms-length relationship between client and vendor with minimal information exchange and trust, and limited, if any, joint decision-making. Thus, while agency theory guides how the goals and actions of the principal and agent can be aligned through contracts and incentives, it does not consider how the social structure of the offshored IS project affects economic actions and outcomes.

We draw on the social embeddednes perspective (MacNeil 1983; Uzzi 1996, 1997) to assert that the relational characteristics underlying the exchange relationship in offshored IS projects have a major impact on their success. This perspective suggests that three key characteristics-namely, joint problem solving, fine-grained information transfer, and trust - lead to superior outcomes, especially when all information cannot be codified and transferred through market mechanisms and each partner in the exchange relationship possesses significant tacit knowledge and domain specialization (MacNeil 1983; Uzzi 1996; Uzzi and Lancaster 2003). These conditions, under which the relational characteristics become especially important, characterize strategic offshore IS projects. Specifically, the onshore firm specializes in the business context in which the system will be used and in the requirements for the system to be developed, while the offshore firm specializes in the development process, including formalizing requirements, translating these requirements into design artifacts, and then building the functional system to 


\begin{tabular}{|c|c|c|}
\hline & Category of Constructs & Constructs (control variables are italicized) \\
\hline \multicolumn{2}{|c|}{ Project Characteristics } & $\begin{array}{l}\text { Project complexity } \\
\text { Requirements uncertainty } \\
\text { Project size } \\
\text { Project duration }\end{array}$ \\
\hline \multicolumn{2}{|c|}{ Agency Factors } & $\begin{array}{l}\text { Granularity of service level agreements } \\
\text { Risk sharing }\end{array}$ \\
\hline \multirow{3}{*}{ 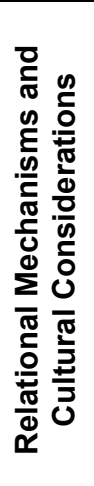 } & $\begin{array}{l}\text { Leveraging relational mechanisms and } \\
\text { aligning norms for organizational work } \\
\text { practices }(\mathrm{H} 1-\mathrm{H} 4)\end{array}$ & $\begin{array}{l}\text { Firm history } \\
\text { Client participation for joint problem solving } \\
\text { Information exchange activities through site visits } \\
\text { Trust of client in vendor for open governance architecture } \\
\text { Shared norms: Client-vendor differences in work practices }\end{array}$ \\
\hline & $\begin{array}{l}\text { Augmenting relational mechanisms } \\
\text { with project leader cultural values }(\mathrm{H} 5)\end{array}$ & $\begin{array}{l}\text { Project leader experience } \\
\text { Espoused cultural values of project leader from vendor firm }\end{array}$ \\
\hline & $\begin{array}{l}\text { Aligning cultural values of client repre- } \\
\text { sentative and project leader }(\mathrm{H} 6)\end{array}$ & $\begin{array}{l}\text { Shared values } \\
\text { Cultural differences of client representative and project leader from } \\
\text { vendor firm }\end{array}$ \\
\hline
\end{tabular}

conform to design specifications (Nicholson and Sahay 2004). We suggest that, under such conditions, projects characterized by relational structures for joint problem solving, fine-grained information transfer, and trust should outperform those that do not have these characteristics.

While the social embeddedness perspective highlights information exchange, joint problem solving, and trust as factors that are critical for successful interorganizational relationships, it says little about the role of shared norms and values. We suggest that higher degrees of social embeddedness should be characterized by shared norms and values between collaborators. Under such conditions, partners are more likely to agree on important goals and how work should be accomplished. Also, shared norms and values facilitate the effective functioning of teams, enabling team members to contribute their expertise toward collaborative tasks (e.g., Earley and Mosakowski 2000; Kirsch et al. 2002). In addition, shared cultural norms and values assist in the transmission of tacit knowledge between partners in the exchange relationship. As we will argue in greater detail later, because offshore IS projects span national boundaries, organizational and national cultural characteristics represent key norms and values that likely influence the effectiveness of collaboration (Krishna et al. 2004; Walsham 2002). Thus, our main argument is that, like information exchange, joint problem solving, and trust, shared cultural norms and values are an important aspect of social embeddedness in offshore IS projects. We now discuss how these mechanisms operate in the context of offshore IS projects. Our model is presented in Figure 1.

\section{Joint Problem Solving: Role of Client Participation}

Client participation in software development is generally instrumental for project success as client members can provide immediate feedback as alternate solutions are explored during the development process (Hartwick and Barki 1994; Ives and Olson 1984). The presence of a client member on an offshore IS project team represents a structure for joint problem solving (Hartwick and Barki 1994). Such structures for joint problem solving are established to generate rapid and explicit feedback and to enrich capabilities for developing effective solutions (Hunton and Beeler 1997). In contrast, market exchange does not provide direct feedback and clients use an exit/stay strategy based on the vendor's performance toward providing a solution. In the context of offshore IS projects, the formal participation of the client on the project team should facilitate problem recognition and resolution, the generation of ideas, and the acceleration of learning. Thus, we hypothesize

H1: Client participation - that is, having a client member on the offshore project team-will positively influence offshore IS project success.

\section{Information Exchange: Role of Site Visits by Client and Vendor}

The IS and project management literatures provide evidence of the importance of knowledge integration for project suc- 


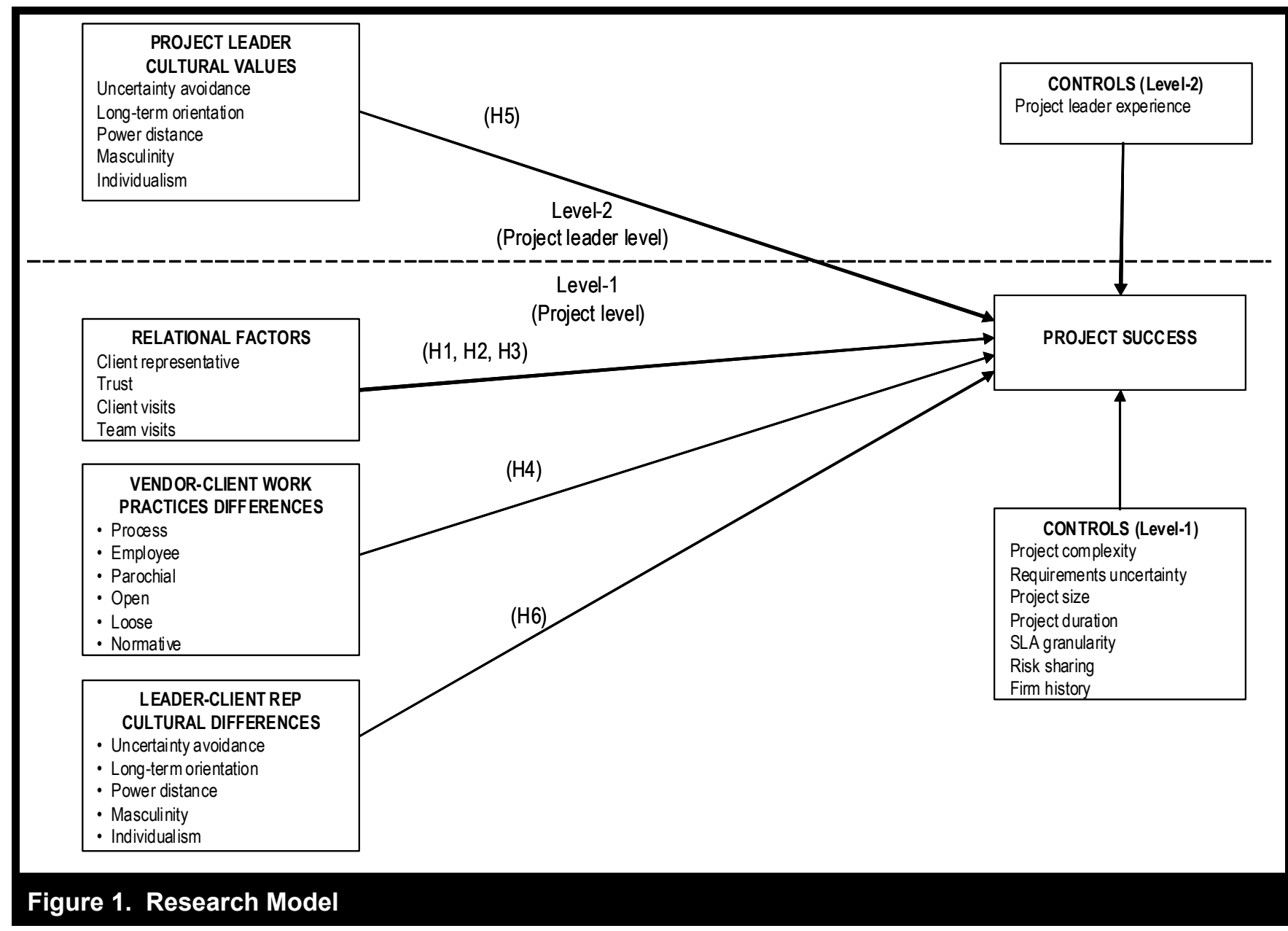

cess and the need to isolate effective mechanisms that facilitate integration in a given context (Mitchell 2006; Nagarajan and Mitchell 1998). For example, Mitchell (2006) identified effective practices for integrating knowledge in enterprise application integration projects. These studies conclude that interaction routines are a key mechanism that enables the exchange of information among parties with complementary knowledge. As suggested earlier, individuals or groups in the client and vendor firm possess specialized knowledge for distinct aspects of the project. Those specializing in requirements determination and business analytics depend on those specializing in programming to implement and monitor their decisions, while those specializing in programming depend on those specializing in business analytics to collect information and make decisions that can, in effect, be implemented. Thus, these relationships call for the transfer of fine-grained information that is unlikely to occur through market exchange mechanisms and requires rich face-to-face interactions to bridge cultural boundaries.
In embedded relationships, the information that is transferred is more proprietary and tacit than in arms-length market exchanges (Inkpen and Tsang 2005). Interaction routines that characterize relational exchange, such as site visits, facilitate access to strategic information and tacit know-how (Nicholson and Sahay 2004). These activities and routines enable the credentialing of information based on the credibility of the source, facilitate its interpretation, and make it possible to appropriately value the information at hand (Uzzi 1996). Such fine-grained information exchange should increase the adaptation, responsiveness, coordination, and learning of partners, which should contribute to the success of offshore IS projects. Thus, we hypothesize

H2: Information exchange activities between the client and vendor - that is, having client site visits to the vendor and vendor site visits to the client-will positively influence offshore IS project success. 


\section{Trust of Client in Vendor: Role of Open Governance Architectures}

Trust represents one party's willingness to be vulnerable to another party (Mayer et al. 1995). Organizations are reluctant to divulge information that is private and strategic in nature and not accessible through markets, as misappropriation of such information can adversely impact their competitiveness (Klein et al. 2007). In order to develop effective software solutions, offshore IS project teams require intimate knowledge of the client firm's business processes, technology architectures, and data resources (Ross and Beath 2006). Trust facilitates the sharing of such private information that is not available through markets and is vulnerable to opportunistic behavior from a self-interested party (Klein et al. 2007; Uzzi and Lancaster 2003). Specifically, trust-based governance creates an open architecture that promotes the exchange of information, expertise, and services that are crucial to achieving outcomes but difficult to contractually stipulate a priori (Uzzi 1996). This exchange is facilitated as trust safeguards against opportunistic behavior by the partner. The free flow of information, facilitated by trust, increases the ability of the partnership to adapt to unforeseen problems. Finally, it creates conditions for benefits to be extended from one partner to the other and for these benefits to be reciprocated by the other in the future. Thus, we hypothesize

\section{H3: Trust of the client in the vendor will positively influence offshore IS project success.}

\section{Shared Norms: Differences in Cultural Norms of Client and Vendor}

Earlier, we highlighted shared norms as an important aspect of social embeddedness. We theorize that differences in cultural norms between the client and vendor firm impede offshore IS project success. Firms with similar cultural norms should be able to economize cognitive resources, time, and attention that are required to interpret complex information and make quality decisions. In fact, shared norms are especially important in contexts where the problem is unique and the uncertainty is high, as in the case of strategic offshore IS projects. Past research on decision-making heuristics (Kahneman and Tversky 1982) is consistent with this theme on how embedded social structures establish common norms and understanding that enhance the capacity of partners to process stimuli, and to gather and process information (Uzzi 1997). Empirical work on cultural similarity in contexts, such as joint ventures and mergers, indicates that differences in cultural norms create psychological hurdles. Consequently, alliances between organizations with similar cultural norms are more likely to be successful than those between organizations with dissimilar ones (Pothukuchi et al. 2002). Moreover, differences in cultural norms make it costly to negotiate positions and to integrate management practices and knowledge - goals that must be effectively accomplished for the success of offshore IS projects (Pothukuchi et al. 2002).

We draw on Hofstede et al.'s (1990) organizational cultural norms to assess the differences in work-related practices between the onshore client and offshore vendor. They isolate six work-related practices that are characteristics of the organizational unit, not the individuals: (1) process-oriented versus result-oriented (contrasts a concern for means with goals); (2) employee-oriented versus job-oriented (contrasts a concern for people with getting the job done); (3) parochial versus professional (contrasts employee identity derived from the organization with profession); (4) open system versus closed system (contrasts organizations based on communication climate); (5) loose control versus tight control (contrasts organizations based on level of internal control); and (6) normative versus pragmatic (contrasts organizations based on rule-orientation with customer-orientation).

Differences in process versus result orientation can create conflicts about the rigidity with which work is organized. Process-oriented work practices tend to be mechanistic whereas result-oriented work practices are more organic (Hofstede et al. 1990; Pothukuchi et al. 2002). Differences can give rise to incompatibility in coordinating work, such as requirement specification, design, and testing. Differences in employee versus job orientation have implications for expectations about delivery schedules and whether employees are pushed to reach project milestones on time (Blake and Mouton 1964). Miscommunication and/or misunderstanding will lead to confusion about such expectations. When client and vendor firms differ on parochial versus professional orientation, the mechanisms for governing work may conflict with each other. As Pothukuchi et al. (2002) note, parochial orientation tends to emphasize clan governance whereas professional orientation emphasizes market governance. Confusion about goal expectations can result when approaches to governance differ. Differences in open versus closed systems across firms are detrimental to project success, particularly given the importance of complete information. Misaligned communication climates hamper the ability of client and vendor firms to interact effectively. Differences in loose versus tight control can lead to conflicts about where decision rights reside. Disagreements often result in distrust that hampers collaboration (Pothukuchi et al. 2002; Putnam and Poole 1987). Finally, differences in normative versus 
pragmatic orientation can give rise to conflicting practices. In sum, to the extent that the onshore client and the offshore vendor differ on these cultural norms, their management tendencies and work structures should be incompatible, misunderstandings and interaction problems should be exacerbated, and the psychological hurdles for collaboration will be high. Thus, we hypothesize

\section{H4: Differences in norms - that is, having differences in work practices between the client and vendor organizations- will negatively influence offshore IS project success.}

\section{Role of Project Leader Values}

A project leader's espoused culture encompasses values that form the basis of their schemata of how the world works (Bartunek and Moch 1987; Earley, 1993). The concept of espoused culture (henceforth referred to as culture) recognizes that individuals of the same national origin may vary in the degree to which they embrace the values associated with their national culture (e.g., Srite and Karahanna 2006). Consequently, the schemata possessed by individuals within the same nation are likely to differ. These schemata translate into patterns of behavior that people exhibit in relating to the world around them (Harris 1994). The five key cultural values are uncertainty avoidance, long-term orientation, power distance, individualism/collectivism, and masculinity/ femininity (Hofstede 1980, 2001). Although Hofstede's work has conceptualized these cultural values at the national level, they have been treated as being espoused at the individual level in much prior work (e.g., Bochner and Hesketh 1994; Cox et al. 1991; Earley 1989, 1993; Gomez et al. 2001; Srite and Karahanna 2006) and consistent with this, we define these constructs at the individual level - that is, espoused culture.

Uncertainty avoidance refers to the degree of tolerance an individual has for uncertainty and ambiguity. High uncertainty avoidance individuals have a low tolerance for uncertainty and prefer structured situations. Uncertainty reduction mechanisms, such as rules, laws, and controls, are highly favored by such individuals. In contrast, low uncertainty avoidance individuals have a high tolerance for uncertainty and ambiguity and such individuals are often open to change, are willing to take risks, and are open to varying opinions on important decisions (Berger 1979; Early and Stubblebine 1989). Long-term orientation refers to the extent to which an individual adheres to forward thinking. High long-term orientation individuals value long-term commitments and this often translates into a degree of rigidity with respect to change. Low long-term orientation individuals place less emphasis on long-term commitments and prefer change to occur more rapidly (Hofstede 1980). Power distance is the extent to which status inequalities are recognized and accepted. Low power distance individuals do not accept that there are status inequalities in hierarchical organizational structures. In contrast, high power distance individuals accept that status inequalities exist and revere those of higher status than themselves (Srite and Karahanna 2006). Individualism/ collectivism refers to the degree to which an individual's social behavior is driven by personal rather than collective goals. Individualistic individuals find it quite acceptable for personal goals to supersede collective goals. Collectivistic individuals emphasize the goals of the collective over their own personal goals (Redding and Baldwin 1991; Srite and Karahanna 2006). Finally, masculinity/femininity is the extent to which emotional gender roles are recognized with respect to work. Individuals with masculine values emphasize work goals, assertiveness, and achievement. In contrast, feminine values include nurturing, concern for others, and quality of life (Hofstede 1980).

We expect project leader cultural values to influence offshore IS project success. Project leaders exhibiting high uncertainty avoidance are likely to aggressively reduce risks, enforce conformance to plans, and reduce deviations from them (Sully de Luque and Sommer 2000). Also, such project leaders are likely to conform to and enforce norms and rules (Shackleton and Ali 1990). In offshore IS projects, uncertainty about how well the project team is adhering to client values or progressing toward meeting client goals will prompt high uncertainty avoidance project leaders to exert tight process and outcome controls to ensure successful project completion. High long-term orientation project leaders value long-term commitments over short-term gains. Such project leaders are likely willing to forego pursuing the project team's goals in order to ensure that client goals are achieved. Prioritizing client goals enables the project team to sustain the vendorclient relationship over time. A high long-term orientation project leader would prevent the team from pursuing its own interests and ensure that team goals are aligned with client goals. High power distance project leaders are likely to recognize the power differential between the vendor and client and, thus, will likely comply with client directives. Project leaders who embrace collectivistic values will place the goals of the client ahead of their own personal goals, thus making them more likely to guide the project in the best interests of the client. Finally, given their emphasis on work goals, project leaders with high masculinity are more likely to stress goal accomplishment by striving to meet project deadlines and deliver a high quality product. Thus, we hypothesize 


\section{H5: Project leader cultural values will influence offshore IS project success.}

\section{Shared Values: Cultural Differences Between Client Representative and Project Leader}

H1 suggested that client representation on offshore teams is preferred. However, simply having a client representative on the team may be insufficient. Important design decisions must also be made with regard to team composition (Ancona and Caldwell 1992; Campion et al. 1993). This is especially critical for offshore IS project teams that span cultural boundaries (Krishna et al. 2004; Walsham 2002). The relational exchange perspective, with its macro focus, says little about how such offshore teams should be designed.

Interpersonal differences play a significant role in facilitating the effective functioning of teams (Harrison et al. 2002). In offshore IS project teams, the concepts of shared values and norms in the relational perspective are reflected in the cultural differences between the client representative and the project leader. As we noted earlier, cultural differences or similarities also mean that the schemata through which these key stakeholders view the world may also be different or similar. The effects of these shared values and norms are expected to be isomorphic across organizational and team levels of analysis, leading to greater offshore IS project success. Although the relationships are expected to be isomorphic across levels of analysis, the underlying mechanisms differ as interpersonal differences take center stage at the team level.

At the team level, collaborative tasks, such as software development, make cultural differences salient as different work patterns emerge during a project. Differences in cultural values can disrupt work efficiency by giving way to incompatible work patterns and creating conflict (Harrison et al. 2002; Lau and Murnighan 1998). For instance, Watson et al. (1993) found that teams with a nationally diverse membership were less efficient than teams with a nationally homogenous membership. In offshore IS project teams, client representatives possess relevant domain knowledge (e.g., understanding of business processes, hierarchical reporting structures) that is needed for successful project completion. With this domain knowledge, client members are charged with evaluating and approving decisions about the functionality of the software project (Kirsch et al. 2002). Project leaders in offshore IS projects determine how work on the project gets accomplished through, for example, task assignment and scheduling of deadlines (Guinan et al. 1998). When a client representative and project leader share similar cultural values, they are more likely to agree on the appropriate work patterns necessary to meet project objectives. This facilitates more efficient project task accomplishment as it provides a common platform for problem solving. Consistent with this idea, team mental model research suggests that shared mental modelsabout how tasks are accomplished-facilitate greater team performance (Mathieu et al. 2000). In contrast, cultural differences between the client representative and project leader can lead to conflicts over how to solve problems and accomplish tasks (Walsham 2002). Even when the client representative and project leader do eventually reach convergence on problem solving and task accomplishment, significant process losses occur as a result of the different schemata by which these parties operate. Divergence in this regard often leads to an inefficient use of time and resources. These inefficiencies hamper offshore IS project success. Thus, we hypothesize

H6: Differences in values-that is, having cultural dissimilarity between the client representative and the project team leader-will negatively influence offshore IS project success.

\section{Method}

We tested our model in a field study of offshore IS projects managed by a leading software vendor in India that has a Level-5 CMMi certification. The selection of this vendor enabled us to control for variance in project cost overruns and client satisfaction due to process maturation levels. The vendor has managed numerous offshore IS projects for clients in various countries, including the United States, Germany, and Japan. In this section, we describe the sample, measurement, and data collection process.

\section{Sample and Participants}

Our sampling frame was a list of 585 software projects that were strategic in nature to U.S. clients, and these projects were completed over a four-year period, starting in July 2001. The projects we targeted were classified as custom development projects by the vendor and, therefore, did not include simple projects that had highly modularized and nearly outof-the-box solutions from the vendor (e.g., systems for standardized billing and payroll processes). Examples of projects included a software solution that would allow a client to do business with some partners by being compliant with a particular process standard (e.g., RosettaNet), a complete human resource information system, and an integrated customer relationship management system following the acquisition of another company by a client company. We provide an overview of a project as an illustration in Appendix A. From the 
585 projects, we selected the 155 that were with U.S. clients because aspects of interest to us, including site visits, trust, and culture, were tracked for these projects. In 24 of the 155 projects, the client representative and project leader had worked together on previous projects; 53 of the 155 project teams had no client representative.

\section{Measurement}

Two indicators of offshore IS project success were included as dependent variables in our model. First, we included project cost overruns as an objective outcome measure of project success. Consistent with Nidumolu (1995), cost overruns were calculated as the percentage difference between actual project costs and budgeted project costs. Actual project cost was measured as a linear composite of three cost components: (1) billed man-hours for the development effort; (2) negotiated billed expenditures related to specialized software, training, conferences, and visits to sites of customers or partners of client firms; and (3) additional expenditures incurred by the client above and beyond the negotiated billed expenses. Project cost overruns are an important indicator of project success because, although a project may be of high quality, the cost of producing the software product may exceed projected costs (Nidumolu 1995). Second, we included client satisfaction with the final product as a second outcome measure of project success. Four months after the projects were delivered, clients provided ratings of their satisfaction with the final product. A four-item scale consistent with Nidumolu (1995) was used to capture client satisfaction.

To capture differences in client-vendor work norms, we measured client firm work practices and vendor firm work practices using the Hofstede et al. (1990) work culture scales. Specifically, we used three-item scales for each of the six dimensions of organizational work practices: process versus result orientation, employee versus job orientation, parochialism versus professionalism, open versus closed system, loose versus tight control, and normative versus pragmatic orientation. Differences in work practices were calculated as the absolute difference in client and vendor responses to each dimension of this scale. Account managers provided responses for vendor-side work practices and business unit managers provided responses for client-side work practices.

Cultural values - namely, uncertainty avoidance, long-term orientation, power distance, individualism/collectivism, and masculinity/femininity — of project leaders and client representatives were measured on a 100-point scale using items from Hofstede (2007) as specified in the VSM 94 manual.
We measured these values at the individual level and calculated client-leader differences as the absolute difference in client and leader responses to each of the five cultural characteristics. For example, power distance is the absolute difference between the leader's and the client representative's power distance scores. We measured client trust in the vendor using a three-item scale adapted from Aulakh et al. (1996).

A dummy variable, Client representative, was used to indicate whether a project team had a client representative present or not. The variable Clientmeet measured the number of times the client visited the project team. Teammeet was measured as the number of times the members of the project team visited the client site. We also coded Teammeet, weighted by the number of team members on each client visit, even if they all traveled at the exact same time and for the exact same duration - the logic is that the more members on the client site, the greater the extent of interaction and information exchange between the vendor and client. The various survey items are shown in Appendix B.

\section{Control Variables}

To safeguard against rival explanations, we specify four sets of control variables: (1) key project characteristics; (2) agency control mechanisms of service level agreements and the nature of risk sharing; (3) self-controls from the level of process maturity; and (4) history effects.

To account for variations in project characteristics, we controlled for three structural aspects: project size, project complexity, and requirements uncertainty (see Keil et al. 2000; Ravichandran and Rai 2000; Wallace et al. 2004). Specifically, project size was measured as lines of code; project complexity was measured using the number of adjusted function points, which adjusts the count of function points by the total ratings of 14 complexity characteristics that account for the different kinds of system requirements and development environments (see Albrecth and Gaffney 1983; Mukhopadhyay et al. 1992); and requirements uncertainty was measured as the number of formal written changes to requirements that were made to the contract. The measure for each of these three project characteristics was obtained from project documents. In addition, we controlled for project duration, which was measured as the number of months taken to complete the project.

To account for differences in agency contractual mechanisms used across projects, we specify granularity of service level agreements and risk sharing as control variables. We select 
these two variables as agency theory and studies that apply this theory to IS project management note that characteristics of formal controls influence the extent to which the agent works in the best interest of the principal (Eisenhardt 1985; Jensen and Meckling 1976; Kirsch 1997). Specifically, service level agreements (SLAs) are one key mechanism that formally define outcome expectations and track actual performance against these expectations. These agreements can differ in monitoring granularity, ranging from detailed specification of expectations (e.g., time and quality for activities) to a much more coarse specification of these expectations (Lewis and Rai 2006). Accordingly, SLA granularity was measured in terms of the detail at which project activities were monitored. We used the following heuristics to assign scores for SLA granularity: a score of 3 for closely monitoring activities using detailed SLAs; a score of 2 for a moderate level of SLA-based monitoring; and a score of 1 for the least granular SLA-based monitoring.

For the second agency factor, risk sharing, we coded the contracts to distinguish among three levels of increasing risk sharing for the vendor to efficiently meet goals for the client: (1) time-and-materials; (2) fixed-price; and (3) fixed-price plus incentives and/or penalties for meeting or missing performance targets. As Gopal et al. (2003) demonstrated, fixed price contracts skew risks toward the vendor and timeand-material contracts place the burden of the risk on the client. Moreover, Ravichandran and Rai (2000) note that rewards and penalties play an important role in the outcomes of systems development projects. Thus, we include a third category of contracts, which we label "fixed-price plus rewards and penalties."

In addition to the client using risk sharing and monitoring to exercise control on the vendor, self-controls can be used by the vendor to control its activities and processes (Choudhury and Sabherwal 2003; Kirsch 1997). We control for the level of process maturity of the vendor, as differing levels of maturity can impact the success of offshore IS projects (see Ravichandran and Rai 2000). Finally, we controlled for two forms of history effects: (1) the project leader's experience with managing offshore IS projects (measured as the number of projects a leader had previously managed); and (2) firm history effects (calculated as the number of previous projects that the vendor had completed for the client firm).

\section{Procedure}

We collected data by working closely with the vendor company. As we were collecting data about projects unfolding in their naturally occurring state in the real world, we sought to collect data at the beginning and end of each project. Survey data on cultural values were collected from project leaders at the beginning and end of the project. Although the leader data were collected at the start and end of each project, we used the first survey filled out by each leader in our analysis. Interestingly, an examination of the correlations of the leader data over time showed them to be highly correlated $(r>.80$ in all cases), thus alleviating concerns related to changing cultural values of the leaders over time.

Data related to project characteristics, agency factors, client representation on teams, differences in organizational work practices, meetings between client and vendors, and client representative cultural values were collected from project documents at the end of the development phase of each project. The combination of perceptual and archival sources of data collection is a major strength of the procedure and adds to the validity. An additional strength of the procedure is that client satisfaction data were collected four months after project completion.

\section{Results}

This section is organized to first provide the results of our preliminary analyses examining reliability and validity; this is followed by an overview of multilevel modeling in general and hierarchical linear modeling, which is the approach used to conduct our analysis; and, finally, we report the results of our model testing.

\section{Preliminary Analysis}

All multi-item measures were adapted from previously validated scales and the results of our factor analysis confirm their convergent and discriminant validity. In addition, the reliability of each measure was greater than 0.70 , thus meeting threshold requirements. Given that the scales used were well-established and these results are consistent with reported findings, we do not provide detailed results in the interest of space. Tables 2 and 3 present the means, standard deviations, and correlations of the constructs in the model, corresponding to the full sample and the subsample with client representation. Metrics of size, complexity, and requirements uncertainty indicated that these projects were indeed quite complex. Also, our sample of projects exhibited quite a bit of a variance on these three key project characteristics. Specifically, the project size and complexity indicate the average number of lines of code to be over 400,000 , with the standard deviation being about 70,000, and the adjusted number of function points to be, on average, over 


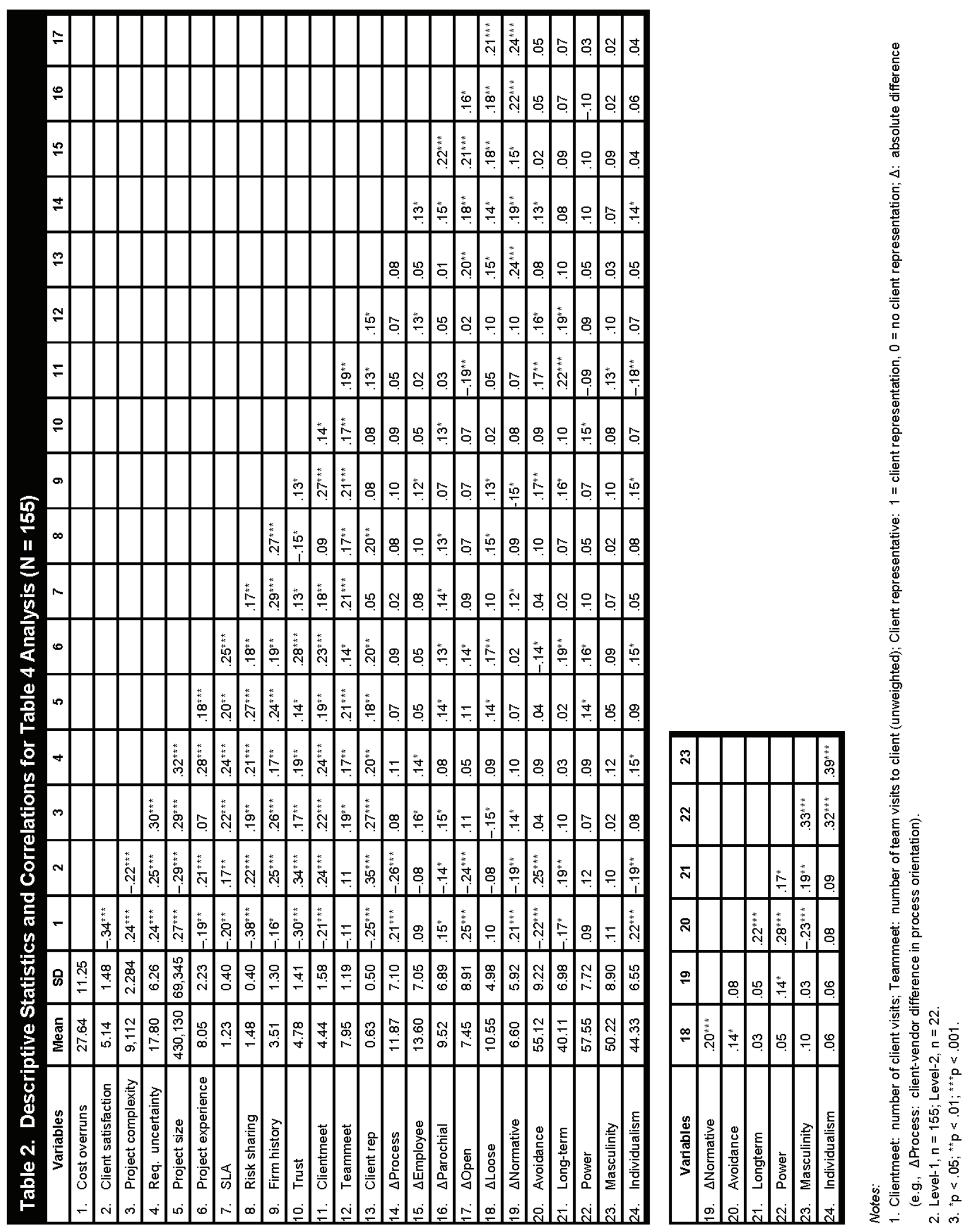




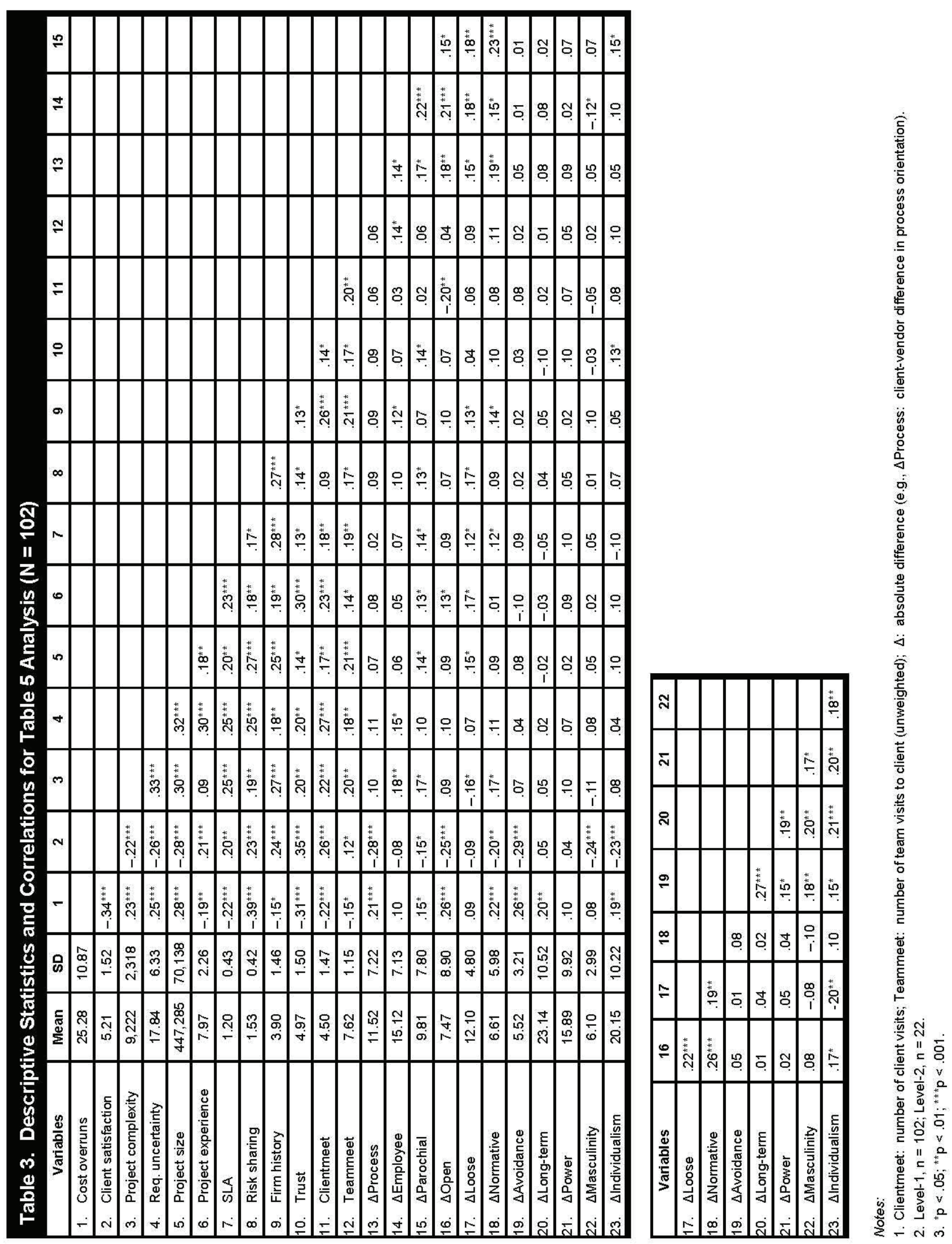


9,000 , with a standard deviation over 2,000. As can be expected, the mean values for the project leader's cultural values (Table 2) are comparable with mean values at the national level for India (Hofstede 2007). However, their standard deviations range from about 7 to 11 , indicating individual variation within India and supporting the notion that cultural values were indeed espoused at the individual level (i.e., by project leaders) in our sample. Also, in examining the differences between the cultural values of client representatives and project leaders, we notice that the pattern of differences is consistent with what is reported in Hofstede (2007) for the United States versus India. However, as was the case with the scores of the project leaders, here too we see substantial variance in the differences, underscoring the importance of espoused cultural values and differences. Further, the scores on various cultural values for both project leaders and client representatives from which the differences were computed were, on average, generally consistent with what is noted by Hofstede (2007). Consistent with prior research, project size, project complexity, and requirements uncertainty are positively correlated with project cost overruns and negatively correlated with client satisfaction; SLA granularity is negatively correlated with project cost overruns and positively correlated with client satisfaction. Client representation on the team, number of client visits to the team, and number of team visits to the client are negatively correlated with project cost overruns and positively correlated with client satisfaction. Differences in work practices between the client and vendor and differences in client-leader cultural values are positively correlated with project cost overruns and negatively correlated with client satisfaction.

\section{Hierarchical Linear Modeling}

Given the multilevel nature of the hypotheses and data, we used random coefficient modeling (RCM) for the analysis (Bliese and Ployhart 2002; Bryk and Raudenbush 1992). Specifically, we used HLM 6.0, a RCM software package, to analyze the data (Bryk and Raudenbush 1992). RCM is wellsuited for analyzing hierarchically nested data. In the current study, the 155 projects were nested within 22 project leaders. Bliese and Hanges (2004) outline several reasons why it is important to model the hierarchically nested structure of the observations in multilevel data. First, ignoring the nested structure of the data results in a failure to model the nonindependence of observations (Bliese and Hanges 2004; Kenny and Judd 1986). Such an approach assumes that there is no between-unit variance on the dependent variable. Consequently, resulting standard errors become artificially small, increasing the likelihood of Type I error (Bliese and Hanges 2004; see also Klein et al. 2000). Second, failure to account for non-independence can result in inflated variance that leads to larger standard errors that increase the risk of Type II error (Bliese and Hanges 2004). Type I and Type II errors pose serious risks because they lead researchers to draw flawed conclusions based on the results of their analyses (Bliese and Hanges 2004; Bryk and Raudenbush 1992; Kenny and Judd 1986). HLM and other RCM tools remedy many of the risks for Type I and Type II errors by explicitly modeling the nonindependence of observations in data.

HLM has been used extensively in the management literature and is beginning to be used in IS research (e.g., Ang et al. 2002). HLM enables the study of relationships within hierarchical units and between units simultaneously (Hofmann 1997). Researchers can examine the effects of unit-level variables on lower-level outcomes and/or examine how unit-level variables affect the relationship between two lower-level variables. Ordinary least squares (OLS) regression approaches do not allow a simultaneous examination of relationships at different levels of analysis. OLS approaches require researchers to either assume zero between-unit variance - if one is interested in lower-level relationships - or assume zero within-unit variance - if one is interested in unitlevel relationships (Klein and Kozlowski 2000). In either case, important information is lost when variance at one level is artificially set to zero. In contrast, HLM employs an empirical Bayes approach to estimate coefficients (Bryk and Raudenbush 1992). Such an approach uses all of the information available across different levels of analysis. Also, HLM partitions the variance in the dependent variable into its lower-level and unit-level components, thus controlling for nonindependence of error terms (Bliese and Hanges 2004; Bryk and Raudenbush 1992). The system of equations that were tested in HLM is shown in Appendix C.

\section{Model Testing}

Table 4 presents the results of the model testing. The control variables relating to project characteristics, ${ }^{3}$ leader characteristics, and agency factors were entered into the model in the first block. Relational factors were entered in the second block, differences in work practices were entered in the third block, and project leader cultural values were entered in the final block. Consistent with prior research, all three project

\footnotetext{
${ }^{3}$ Project duration was nonsignificant in all analyses. Therefore, it was dropped in the interest of model parsimony.
} 
characteristics had a positive influence on project cost overruns and a negative influence on client satisfaction. The agency factors, SLA granularity and incentive structures, had negative effects on cost overruns and a positive influence on client satisfaction. Finally, project leader experience had a negative influence on cost overruns and a positive influence on client satisfaction. These control variables explained 10 percent and 8 percent of the variance in cost overruns and client satisfaction, respectively.

Entering the relational factors into the model explained an additional 6 percent and 7 percent of the variance in project cost overruns and client satisfaction, respectively (see Model 2). Model 3, which includes the variables on differences in work practices, explained an additional 8 percent and 10 percent of the variance in project cost overruns and client satisfaction over and above Model 2. Consistent with H1, the participation of a client representative on the team (Client representative) negatively influenced project cost overruns $\left(\gamma_{100}=-.16, p<.01\right)$ and positively influenced client satisfaction $\left(\gamma_{100}=.24, \mathrm{p}<.001\right)$. Consistent with $\mathrm{H} 2$, the number of client visits to the vendor firm (Clientmeet) negatively influenced project cost overruns $\left(\gamma_{80}=-.14, \mathrm{p}<\right.$ $.01)$ and positively influenced client satisfaction $\left(\gamma_{80}=.16, p\right.$ $<.05)$; however, the relationship between the number of team visits to the client site (Teammeet) and project success was nonsignificant $\left(\gamma_{90}=.04, \mathrm{p}=\mathrm{ns} ; \gamma_{90}=.06, \mathrm{p}=\mathrm{ns}\right.$ for project cost overruns and client satisfaction, respectively). As predicted in $\mathrm{H} 3$, trust was negatively related to project cost overruns $\left(\gamma_{70}=-.24, \mathrm{p}<.001\right)$ and positively related to client satisfaction $\left(\gamma_{70}=.26, \mathrm{p}<.001\right)$.

$\mathrm{H} 4$ predicted that differences in work practices between the client and vendor firms would negatively influence project success. Three of the five work practice cultural differences variables played a role in the direction predicted: Process $\left(\gamma_{110}=.13, \mathrm{p}<.05\right)$, Open $\left(\gamma_{140}=.16, \mathrm{p}<.05\right)$, and Normative $\left(\gamma_{160}=.14, p<.05\right)$ for project cost overruns; and Process $\left(\gamma_{110}=-.16, \mathrm{p}<.05\right)$, Open $\left(\gamma_{140}=-.15, \mathrm{p}<.05\right)$, and Normative $\left(\gamma_{160}=-.12, p<.05\right)$ for client satisfaction. The positive coefficients in the case of project cost overruns and the negative coefficients in the case of client satisfaction support $\mathrm{H} 4$ as larger values represent greater differences on each cultural norm. Thus, H4 is partially supported.

H5 predicted that project leader cultural values would be important for ensuring project success. To test this hypothesis, we examined the relationship between project leader cultural values and the two outcome variables in the entire sample of projects. ${ }^{4}$ These results relate to block 4 in Table 4 . Only one of the project leader cultural values, namely longterm orientation, had a significant effect on both outcomes. All other leader cultural values were not significant. The project leader cultural values explained a modest additional variance of 3 percent in project cost overruns and client satisfaction. The results shown in Table 4 are what were obtained after dropping the nonsignificant values and reestimating the model. Thus, H5 received weak support.

As noted in the build up to H6, having a client member on a project team may be insufficient for realizing the benefits of such a team design. Specifically, we suggested that cultural differences between the client member and the project leader could influence the effectiveness with which project teams are able to carry out their work. Using the sample of 102 projects with a client representative, we tested $\mathrm{H} 6$ by examining the effects of client member and project leader cultural differences on the outcome variables. The results of the analysis are presented in Table 5. Client representativeproject leader cultural differences explained an additional variance of 13 percent in both cost overruns and client satisfaction over and above the relational factors and the work practices differences between the client and vendor. Client representative-project leader differences on uncertainty avoidance $\left(\gamma_{160}=.15, \mathrm{p}<.05\right)$, long-term orientation $\left(\gamma_{170}=\right.$ $.17, \mathrm{p}<.05)$, and individualism/collectivism $\left(\gamma_{200}=.13, \mathrm{p}<\right.$ $.05)$ positively influence project cost overruns, while their differences on uncertainty avoidance $\left(\gamma_{160}=-.19, \mathrm{p}<.01\right)$, masculinity/femininity $\left(\gamma_{190}=-.16, \mathrm{p}<.05\right)$, and individualism/collectivism $\left(\gamma_{200}=-.14, \mathrm{p}<.05\right)$ negatively influence client satisfaction, thus supporting H6.

An interesting observation is that, although the power distance differential is high, it does not play a significant role in predicting either cost overruns or client satisfaction, perhaps because the project leaders are quite deferential given the high power distance score among the project leaders. The large differences in individualism/collectivism and long-term orientation play a role in influencing one or both outcomes. Although the differences in uncertainty avoidance and masculinity/femininity are substantially smaller than the other differences, these differences influence the outcomes, with the former influencing both outcomes. Overall, this suggests that cultural differences, with the exception of power distance, both big and small, influence objective (cost overruns) and subjective (client satisfaction) measures of offshore IS project success.

\footnotetext{
${ }^{4}$ Note that the cultural characteristics were based on the 22 project leaders.
} 


\begin{tabular}{|c|c|c|c|c|c|c|c|c|}
\hline & \multicolumn{4}{|c|}{ Cost Overruns } & \multicolumn{4}{|c|}{ Client Satisfaction } \\
\hline & Model 1 & Model 2 & Model 3 & Model 4 & Model 1 & Model 2 & Model 3 & Model 4 \\
\hline $\mathrm{R}^{2}$ & .10 & .16 & .24 & .27 & .08 & .15 & .25 & .28 \\
\hline$\Delta R^{2}$ & .10 & .06 & .08 & .03 & .08 & .07 & .10 & .03 \\
\hline Block 1: & $\mathrm{Y}$ & $\mathrm{Y}$ & $\mathrm{V}$ & $\mathrm{Y}$ & $\mathrm{Y}$ & $\mathrm{Y}$ & $\mathrm{r}$ & $\mathrm{Y}$ \\
\hline \multicolumn{9}{|l|}{ Project Characteristics } \\
\hline Project complexity $\left(y_{10}\right)$ & $.17^{*}(.020)$ & $.15^{*}(.021)$ & $.14^{*}(.022)$ & $.14^{*}(.022)$ & $-.14^{*}(.028)$ & $-.13^{*}(.030)$ & $-.10(.032)$ & $-.08(.033)$ \\
\hline Requirements uncertainty $\left(\gamma_{20}\right)$ & $.18^{\star}(.022)$ & $.17^{\star}(.023)$ & $.08(.024)$ & $.08(.024)$ & $-.17^{\star}(.025)$ & $-.15^{*}(.026)$ & $-.08(.028)$ & $-.08(.028)$ \\
\hline Project size $\left(\gamma_{30}\right)$ & $.21^{* \star}(.027)$ & $.20^{* *}(.029)$ & $.14^{*}(.030)$ & $.14^{*}(.030)$ & $-.19^{* *}(.031)$ & $.16^{*}(.032)$ & $.13^{*}(.033)$ & $.13^{*}(.033)$ \\
\hline \multicolumn{9}{|l|}{ Project Leader Characteristics } \\
\hline Project leader experience $\left(V_{01}\right)$ & $-.13^{*}(.020)$ & $.08(.022)$ & $.05(.023)$ & $.15(.023)$ & $.14^{*}(.021)$ & $.05(.022)$ & $.03(.023)$ & $.03(.023)$ \\
\hline \multicolumn{9}{|l|}{ Agency Factors } \\
\hline Service level agreements $\left(\gamma_{40}\right)$ & $-.13^{*}(.028)$ & $.07(.029)$ & $.05(.030)$ & $.05(.023)$ & $.14^{*}(.021)$ & $.05(.022)$ & $.03(.023)$ & $.03(.023)$ \\
\hline Risk sharing $\left(\gamma_{50}\right)$ & $-.28^{\star \star \star}(.020)$ & $-.25^{\star \star \star}(.027)$ & $-.20^{\star *}(.028)$ & $-.20^{\star *}(.029)$ & $.15^{*}(.027)$ & $.14^{*}(.028)$ & $.05(.029)$ & $.04(.030)$ \\
\hline \multicolumn{9}{|l|}{ Block 2: Relational Factors } \\
\hline Firm history $\left(V_{60}\right)$ & & $-.10(.024)$ & $-.07(.025)$ & $-.06(.026)$ & & $.16^{*}(.012)$ & $.14^{*}(014)$ & $.14^{*}(.014)$ \\
\hline Trust $\left(\mathrm{V}_{70}\right)$ & & $-.24^{\star \star \star}(.020)$ & $-.20^{\star *}(.023)$ & $-.19^{\star *}(.023)$ & & $.26^{\star \star \star}(.016)$ & $.21^{* *}(.017)$ & $.21^{* *}(.017)$ \\
\hline Clientmeet $\left(\mathrm{\gamma}_{80}\right)$ & & $-.14^{*}(.017)$ & $-.13^{*}(.018)$ & $-.13^{*}(.018)$ & & $.16^{*}(.018)$ & $.15^{\star}(.017)$ & $.15^{*}(.017)$ \\
\hline Teammeet $\left(\mathrm{Y}_{90}\right)$ & & $.04(.023)$ & $.04(.025)$ & $.04(.026)$ & & $.06(.020)$ & $.05(.021)$ & $.05(.020)$ \\
\hline Client representative $\left(\mathrm{V}_{100}\right)$ & & $-.16^{\star \star}(.019)$ & $-.16^{\star \star}(.019)$ & $-.15^{\star}(.018)$ & & $.24^{\star \star *}(.020)$ & $.24^{* \star *}(.020)$ & $.24^{\star * *}(.020)$ \\
\hline \multicolumn{9}{|c|}{ Block 3: Vendor-Client Firm Work Practices Differences } \\
\hline$\Delta$ Process $\left(\mathrm{Y}_{110}\right)$ & & & $.13^{*}(.015)$ & $.13^{*}(.015)$ & & & $-.16^{*}(.021)$ & $-.15^{\star}(.020)$ \\
\hline$\Delta$ Employee $\left(\mathrm{\gamma}_{120}\right)$ & & & $.04(.023)$ & $.04(.025)$ & & & $.02(.011)$ & $.02(.013)$ \\
\hline$\Delta$ Parochial $\left(\mathrm{Y}_{130}\right)$ & & & $.05(.021)$ & $.05(.022)$ & & & $.07(.024)$ & $.07(.023)$ \\
\hline$\Delta$ Open $\left(\mathrm{Y}_{140}\right)$ & & & $.16^{*}(.018)$ & $.15^{\star}(.018)$ & & & $-.15^{\star}(.019)$ & $-.14^{*}(.020)$ \\
\hline$\Delta$ Loose $\left(\mathrm{Y}_{150}\right)$ & & & $.03(.018)$ & $.03(.017)$ & & & $.02(.024)$ & $.00(.025)$ \\
\hline$\Delta$ Normative $\left(\mathrm{y}_{160}\right)$ & & & $.14^{*}(.017)$ & $.13^{*}(.017)$ & & & $-.12^{*}(.023)$ & $-.12^{*}(.023)$ \\
\hline \multicolumn{9}{|c|}{ Block 4: Project Leader Cultural Values } \\
\hline Uncertainty avoidance $\left(\mathrm{V}_{02}\right)$ & & & & NS & & & & NS \\
\hline Long-term orientation $\left(\mathrm{V}_{03}\right)$ & & & & $-.13^{*}(.010)$ & & & & $.13^{* *}(.011)$ \\
\hline Power distance $\left(\mathrm{V}_{04}\right)$ & & & & NS & & & & NS \\
\hline Masculinity $\left(\mathrm{Y}_{05}\right)$ & & & & NS & & & & NS \\
\hline Individualism $\left(\mathrm{Y}_{06}\right)$ & & & & NS & & & & NS \\
\hline
\end{tabular}

Notes:

1. Italicized variables are controls. Client representative: $1=$ client representation $0=$ no client representation; Clientmeet: number of client visits; Teammeet: number of team visits to client; $\Delta$ : absolute difference (e.g., $\Delta$ Process: client-vendor difference in process orientation); Standard errors are in parentheses.

2. Level-1, $\mathrm{n}=155$; level-2, $\mathrm{n}=22$.

3. ${ }^{*} p<.05 ;{ }^{* *} p<.01 ;{ }^{* * *} p<.001$. 


\section{Table 5. HLM Model Predicting Cost Overruns and Satisfaction: Projects with Client} Representation ( $\mathbf{N}=102)$

\begin{tabular}{|c|c|c|c|c|c|c|c|c|}
\hline & \multicolumn{4}{|c|}{ Cost Overruns } & \multicolumn{4}{|c|}{ Client Satisfaction } \\
\hline & Model 1 & Model 2 & Model 3 & Model 4 & Model 1 & Model 2 & Model 3 & Model 4 \\
\hline $\mathrm{R}^{2}$ & .12 & .20 & .27 & .40 & .11 & .20 & .28 & .41 \\
\hline$\Delta \mathrm{R}^{2}$ & .12 & .08 & .07 & .13 & .11 & .09 & .08 & .13 \\
\hline Block 1: & Y & $\mathrm{r}$ & v & $\mathrm{Y}$ & $\mathrm{r}$ & $\mathrm{Y}$ & Y & $\mathrm{r}$ \\
\hline \multicolumn{9}{|l|}{ Project Characteristics } \\
\hline Project complexity $\left(y_{10}\right)$ & $.18^{*}(.027)$ & $.15^{*}(.030)$ & $.16^{*}(.030)$ & $.14^{*}(.031)$ & $-.15^{\star}(.025)$ & $-.13^{*}(.028)$ & $.12^{*}(.028)$ & $.12^{*}(.028)$ \\
\hline Requirements uncertainty $\left(V_{20}\right)$ & $.18^{\star *}(.021)$ & $.16^{*}(.023)$ & $.17^{*}(.023)$ & $.14^{*}(.024)$ & $-.18^{* *}(.020)$ & $-.16^{*}(.023)$ & $-.15^{*}(.025)$ & $-.15^{\star}(.025)$ \\
\hline Project size $\left(\gamma_{30}\right)$ & $.21^{* \star}(.021)$ & $.17^{* *}(.024)$ & $.17^{* \star}(.024)$ & $.15^{*}(.026)$ & $-.18^{\star *}(.022)$ & $-.15^{\star}(.022)$ & $-.14^{*}(.024)$ & $-.14^{\star}(.024)$ \\
\hline \multicolumn{9}{|l|}{ Project Leader Characteristics } \\
\hline Project leader experience $\left(V_{01}\right)$ & $-.13^{*}(.018)$ & $.03(.022)$ & $.03(.022)$ & $.04(.023)$ & $.13^{*}(.014)$ & $.13^{*}(.014)$ & $.03(.022)$ & $.01(.023)$ \\
\hline \multicolumn{9}{|l|}{ Agency Factors } \\
\hline Service level agreements $\left(\gamma_{40}\right)$ & $-.15^{\star}(.021)$ & $-.14^{*}(.028)$ & $-.14^{*}(.028)$ & $-.13^{*}(.029)$ & $.16^{*}(.020)$ & $.16^{*}(.020)$ & $.15^{*}(.022)$ & $.14^{*}(.023)$ \\
\hline Risk sharing $\left(\gamma_{50}\right)$ & $-.29^{\star \star \star}(.020)$ & $-.27^{\star \star \star}(.022)$ & $-.26^{\star \star \star}(.023)$ & $-.25^{\star \star \star}(.026)$ & $.20^{* *}(.021)$ & $.20^{\star *}(.021)$ & $.18^{\star \star}(.022)$ & $.17^{*}(.024)$ \\
\hline \multicolumn{9}{|l|}{ Block 2: Relational Factors } \\
\hline Firm history $\left(\mathrm{V}_{60}\right)$ & & $-.03(.022)$ & $-.03(.022)$ & $-.03(.023)$ & & $.18^{*}(.012)$ & $.15^{\star}(.014)$ & $.13^{*}(.015)$ \\
\hline Trust $\left(\mathrm{Y}_{70}\right)$ & & $-.28^{\star \star *}(.018)$ & $-.22^{\star \star *}(.018)$ & $-.18^{* *}(.020)$ & & $.29^{\star \star \star}(.012)$ & $.26^{\star \star \star}(.014)$ & $.21^{* *}(.017)$ \\
\hline Clientmeet $\left(\mathrm{Y}_{80}\right)$ & & $-.17^{\star *}(.019)$ & $-.14^{*}(.019)$ & $-.13^{*}(.020)$ & & $.17^{* *}(.012)$ & $.16^{*}(.013)$ & $.14^{*}(.015)$ \\
\hline Teammeet $\left(\mathrm{Y}_{90}\right)$ & & $.04(.011)$ & $.03(.011)$ & $.02(.012)$ & & $.03(.009)$ & $.03(.009)$ & $.02(.010)$ \\
\hline \multicolumn{9}{|c|}{ Block 3: Vendor-Client Firm Work Practices Differences } \\
\hline$\Delta$ Process $\left(\mathrm{Y}_{100}\right)$ & & & $.15^{\star}(.014)$ & $.14^{*}(.013)$ & & & $-.16^{*}(.013)$ & $-.15^{\star}(.014)$ \\
\hline$\Delta$ Employee $\left(\mathrm{Y}_{110}\right)$ & & & $.03(.020)$ & $.02(.018)$ & & & $-.15^{\star}(.010)$ & $-.14^{*}(.013)$ \\
\hline$\Delta$ Parochial $\left(\mathrm{Y}_{120}\right)$ & & & $.03(.010)$ & $.02(.012)$ & & & $-.03(.018)$ & $-.02(.020)$ \\
\hline$\Delta$ Open $\left(\mathrm{Y}_{130}\right)$ & & & $.19^{* *}(.013)$ & $.16^{*}(.015)$ & & & $-.16^{*}(.018)$ & $-.15^{\star}(.019)$ \\
\hline$\Delta$ Loose $\left(\mathrm{Y}_{140}\right)$ & & & $.03(.010)$ & $.04(.012)$ & & & $-.03(.010)$ & $-.02(.014)$ \\
\hline$\Delta$ Normative $\left(\mathrm{V}_{150}\right)$ & & & $.14^{*}(.016)$ & $.13^{*}(.017)$ & & & $-.17^{*}(.014)$ & $-.14^{*}(.015)$ \\
\hline \multicolumn{9}{|c|}{ Block 4: Project Leader Cultural Values } \\
\hline$\Delta$ Uncertainty avoidance $\left(\mathrm{V}_{160}\right)$ & & & & $.15^{*}(.010)$ & & & & $-.19^{* *}(.010)$ \\
\hline$\Delta$ Long-term orientation $\left(\mathrm{y}_{170}\right)$ & & & & $.17^{\star}(.011)$ & & & & NS \\
\hline$\Delta$ Power distance $\left(\mathrm{Y}_{180}\right)$ & & & & NS & & & & NS \\
\hline$\Delta$ Masculinity $\left(\mathrm{Y}_{190}\right)$ & & & & NS & & & & $-.16^{*}(.014)$ \\
\hline$\Delta$ Individualism $\left(\mathrm{Y}_{200}\right)$ & & & & $.13^{*}(.011)$ & & & & $-.14^{*}(.012)$ \\
\hline
\end{tabular}

Notes:

1. Italicized variables are controls. Clientmeet: number of client visits; Teammeet: number of team visits to client; $\Delta$ : absolute difference (e.g., $\Delta$ Process: clientvendor difference in process orientation; $\Delta$ Uncertainty avoidance: client representative-project leader difference on espoused uncertainty avoidance); Standard errors are in parentheses.

2. Level-1, $\mathrm{n}=102$; level-2, $\mathrm{n}=22$.

3. ${ }^{*} \mathrm{p}<.05 ;{ }^{* *} \mathrm{p}<.01 ;{ }^{* * *} \mathrm{p}<.001$. 


\section{Post Hoc Analysis}

Given the weak support for H5 and given that we theorized that it was the cultural differences (project leader versus client representative), rather than the project leader cultural values, that played a role when a client representative was present, we conducted a post hoc analysis to determine the conditions under which project leader cultural values might have an impact. To accomplish this, we examined the cross-level effects of project leader cultural values in the 102 projects with a client representative. There were no significant crosslevel effects for project leader cultural values. We then examined the cross-level effects of project leader cultural values using the subsample of projects without client representation $(n=53)$ and found significant results. This suggests possible cross-level moderation such that the leader's cultural values are significant in the absence of a client representative on the project team and nonsignificant otherwise. We also tested the interaction of Client representative and cultural values of the project leader using the pooled data $(\mathrm{n}=155)$ and found a similar pattern.

Table 6 presents the results of the analysis and Appendix D reports the correlations for the subsample of projects with no client representative. While much of these results were similar to what was observed in Table 4, the key differences were observed in the importance of various project leader cultural values. The project leader cultural values explain an additional 11 percent and 12 percent of the variance (beyond what was explained by control variables, relational factors, and work practices differences) in project cost overruns and client satisfaction respectively. As illustrated in Model 3 of Table 6, project leader uncertainty avoidance $\left(\gamma_{02}=.16, \mathrm{p}<\right.$ $.05)$, long-term orientation $\left(\gamma_{03}=-.13, \mathrm{p}<.05\right)$, and masculinity/femininity $\left(\gamma_{05}=-.17, \mathrm{p}<.05\right)$ have significant cross-level effects on project cost overruns. Project leader uncertainty avoidance $\left(\gamma_{02}=.18, \mathrm{p}<.01\right)$, long-term orientation $\left(\gamma_{03}=.16, \mathrm{p}<.05\right)$, and power distance $\left(\gamma_{04}=.14, \mathrm{p}<.05\right)$ have significant cross-level effects on client satisfaction. With the exception of the positive coefficient for uncertainty avoidance, the other significant coefficients are in the direction we might expect. Overall, based on these results, we can conclude that in the absence of client representation on the team, project leader espoused cultural values are related to offshore IS project success.

\section{Discussion}

The objective of this research was to enhance our understanding of offshore IS project success by incorporating the role of relational and cultural factors. We sought to achieve this objective by integrating the social embeddedness perspective into the IS offshoring literature. Our results provide evidence that offshore IS projects should be managed with a systematic emphasis on relational and cultural factors in addition to a focus on factors derived from agency theory. These relational and cultural factors establish a social context for effective collaboration. Cultural factors - at the level of partnering firms and of project leader and client representative - must be actively managed to increase the success of offshore IS projects. The insights and theoretical contributions that emerge from our study relate to how and why (1) relational factors augment the role of economic contractual mechanisms and project characteristics in achieving IS offshore project success; (2) team leaders' espoused cultural values influence success; (3) differences in organizational cultural norms between the client and vendor firm hinders success; and (4) differences in espoused cultural values between team leader and client representative on the team impedes success for projects with a client representative.

\section{Theoretical Contributions}

This research makes several important contributions to the IS offshoring literature. It demonstrates that offshore IS projects should not be managed with a focus on agency factors only. It brings together the relational and cultural perspectives to enrich the social embeddedness perspective and generate complementary insights on how offshore IS projects should be managed. It identifies the role of relational factors, cultural values of the project leader, and cultural differences at the organizational and team levels. We highlight each of these contributions next.

\section{Role of Relational Factors}

Our results indicate that the management of offshore IS projects should not be limited to dealing with agency concerns of self-interested behavior but must be augmented to embed economic client-vendor interactions in a supportive relational context. While agency factors and project characteristics enhance offshore IS project success, they explain a limited proportion of variance in cost overruns and client satisfaction. In fact, the results show that the addition of relational factors to the set of project characteristics and agency factors significantly enhances the variance explained in offshore IS project success $\left(\Delta \mathrm{R}^{2}=.06\right.$ for cost overruns; $\Delta \mathrm{R}^{2}=.07$ for client satisfaction). Thus, these results demonstrate the importance of managing the relational context in which the client and vendor exchange information and knowledge, solve problems, and make decisions. 


\section{Table 6. HLM Model Predicting Cost Overruns and Satisfaction: Projects with No Client} Representation (N= 53)

\begin{tabular}{|c|c|c|c|c|c|c|}
\hline & \multicolumn{3}{|c|}{ Cost Overruns } & \multicolumn{3}{|c|}{ Client Satisfaction } \\
\hline & Model 1 & Model 2 & Model 3 & Model 1 & Model 2 & Model 3 \\
\hline $\mathrm{R}^{2}$ & .10 & .24 & .35 & .10 & .25 & .37 \\
\hline$\Delta \mathrm{R}^{2}$ & 10 & .14 & .11 & .10 & .15 & .12 \\
\hline Block 1: & $\mathrm{y}$ & $\mathrm{Y}$ & $\mathrm{y}$ & $\mathrm{y}$ & $\mathrm{v}$ & $\mathrm{r}$ \\
\hline \multicolumn{7}{|l|}{ Project Characteristics } \\
\hline Project complexity $\left(\gamma_{10}\right)$ & $.16^{*}(.030)$ & $.15^{\star}(.030)$ & $.15^{\star}(.030)$ & $-.14^{\star}(.027)$ & $-.13^{*}(.028)$ & $.12^{*}(.028)$ \\
\hline Requirements uncertainty $\left(\mathrm{V}_{20}\right)$ & $.17^{* *}(.022)$ & $.16^{*}(.023)$ & $.14^{*}(.025)$ & $-.17^{\star \star}(.020)$ & $-.16^{*}(.023)$ & $-.15^{\star}(.025)$ \\
\hline Project size $\left(\gamma_{30}\right)$ & $.20^{* *}(.022)$ & $.17^{* *}(.024)$ & $.14^{\star}(.025)$ & $-.18^{* *}(.021)$ & $-.15^{*}(.022)$ & $-.14^{*}(.024)$ \\
\hline \multicolumn{7}{|l|}{ Project Leader Characteristics } \\
\hline Project leader experience $\left(V_{01}\right)$ & $-.12^{*}(.017)$ & $.04(.022)$ & $.05(.022)$ & $.12^{*}(.015)$ & $.02(.021)$ & $.01(.022)$ \\
\hline \multicolumn{7}{|l|}{ Agency Factors } \\
\hline Service level agreements $\left(\gamma_{40}\right)$ & $-.13^{*}(.028)$ & $-.12^{*}(.029)$ & $-.13^{*}(.029)$ & $.15^{\star}(.026)$ & $.14^{*}(.029)$ & $.13^{*}(.029)$ \\
\hline Risk sharing $\left(Y_{50}\right)$ & $-.27^{* \star *}(.027)$ & $-.23^{\star \star \star}(.028)$ & $-.24^{\star \star *}(.028)$ & $.21^{* *}(.018)$ & $.19^{\star *}(.019)$ & $.17^{*}(.020)$ \\
\hline \multicolumn{7}{|c|}{ Block 2: Relational Factors and Vendor-Client Work Practices Differences } \\
\hline Firm history $\left(V_{60}\right)$ & & $-.02(.017)$ & $-.02(.018)$ & & $.13^{*}(.015)$ & $.12^{*}(.018)$ \\
\hline Trust $\left(\mathrm{V}_{70}\right)$ & & $-.24^{\star \star *}(.019)$ & $-.20^{\star \star}(.021)$ & & $.24^{\star \star \star}(.015)$ & $.20^{* *}(.018)$ \\
\hline Clientmeet $\left(\mathrm{Y}_{80}\right)$ & & $-.15^{*}(.020)$ & $-.14^{*}(.021)$ & & $.14^{*}(.013)$ & $.13^{*}(.015)$ \\
\hline Teammeet $\left(\mathrm{Y}_{90}\right)$ & & $.02(.010)$ & $.01(.010)$ & & $.03(.010)$ & $.01(.012)$ \\
\hline$\Delta$ Process $\left(\mathrm{Y}_{100}\right)$ & & $.16^{*}(.014)$ & $.15^{\star}(.015)$ & & $-.15^{*}(.013)$ & $-.14^{*}(.015)$ \\
\hline$\Delta$ Employee $\left(\mathrm{V}_{110}\right)$ & & $.04(.020)$ & $.02(.018)$ & & $-.14^{*}(.011)$ & $-.13^{*}(.013)$ \\
\hline$\Delta$ Parochial $\left(\mathrm{Y}_{120}\right)$ & & $.05(.018)$ & $.04(.015)$ & & $-.05(.018)$ & $-.04(.019)$ \\
\hline$\Delta$ Open $\left(\mathrm{V}_{130}\right)$ & & $.18^{* *}(.017)$ & $.15^{\star}(.018)$ & & $-.16^{*}(.018)$ & $-.15^{\star}(.019)$ \\
\hline$\Delta$ Loose $\left(\mathrm{y}_{140}\right)$ & & $.03(.010)$ & $.03(.011)$ & & $-.03(.010)$ & $-.03(.011)$ \\
\hline$\Delta$ Normative $\left(\mathrm{V}_{150}\right)$ & & $.14^{*}(.016)$ & $.13^{*}(.018)$ & & $-.16^{*}(.015)$ & $-.14^{*}(.018)$ \\
\hline \multicolumn{7}{|c|}{ Block 3: Project Leader Cultural Values } \\
\hline Uncertainty avoidance $\left(\mathrm{V}_{02}\right)$ & & & $.16^{*}(.021)$ & & & $.18^{* *}(.018)$ \\
\hline Long-term orientation $\left(\mathrm{Y}_{03}\right)$ & & & $-.13^{*}(.014)$ & & & $.16^{*}(.013)$ \\
\hline Power distance $\left(\mathrm{Y}_{04}\right)$ & & & $.04(.020)$ & & & $.14^{*}(.017)$ \\
\hline Masculinity $\left(\mathrm{V}_{05}\right)$ & & & $-.17^{*}(.013)$ & & & $.07(.014)$ \\
\hline Individualism $\left(\mathrm{Y}_{06}\right)$ & & & $.02(.013)$ & & & $.01(.012)$ \\
\hline
\end{tabular}

\section{Notes:}

1. Italicized variables are controls. Clientmeet: number of client visits; Teammeet: number of team visits to client; $\Delta$ : absolute difference (e.g., $\Delta$ Process: clientvendor difference in process orientation); Standard errors are in parentheses.

2. Level-1, $\mathrm{n}=53$; level-2, $\mathrm{n}=22$.

3. ${ }^{*} \mathrm{p}<.05 ;{ }^{* *} \mathrm{p}<.01 ;{ }^{* * *} \mathrm{p}<.001$. 
In terms of specific relational mechanisms, our results indicate that the success of offshore IS projects is enhanced by client representation on project teams, information exchange through client visits to the vendor site, and governance based on client trust in the vendor. The results point to the importance of active immersion by the client in the organizational context of the vendor in which development work occurs. However, our results do not provide evidence that vendor visits to the client firm impact offshore IS project success. This is possibly because vendor visits to the client site may tend to be more scripted, may involve a subset of the team, and may not receive the full attention of the client due to the natural demands and interruptions that are likely to occur in the day-to-day work environment. Finally, client trust in the vendor enhances the success of offshore IS projects, as it creates the conditions for fine-grained information exchange without fear of opportunism. Thus, although some of these relational mechanisms represent costs, such as those incurred from travel by the client to the vendor site, they are effective investments that pay off by reducing cost overruns and increasing client satisfaction.

\section{Role of Differences in Work Practices Between Client and Vendor Firms}

Our results provide evidence that shared norms between partnering firms contribute to the success of offshore IS projects above and beyond the effect of the three relational factors of joint problem solving, information exchange, and trust. The inclusion of shared norms in our model further increased the explained variance by 8 percent for cost overruns and by 10 percent for client satisfaction. Specifically, we found that offshore IS project success is influenced by differences between the client and vendor on three norms:

(1) organization of work being oriented toward processes or results; (2) communication climate being open or closed; and (3) internal control being loose or tight. Differences on the other norms related to employee versus job orientation, parochialism versus professionalism, and normativeness versus pragmatism were not found to significantly impact cost overruns or client satisfaction.

The findings suggest that differences between the client and vendor in how work is organized - process-oriented versus result-oriented - compounds the difficulties of coordination of activities for requirement specification, software design, and testing. While process-oriented firms prefer to establish detailed processes and interaction routines to coordinate work with their partner, result-oriented firms will prefer to negotiate roles and responsibilities for outcomes with their partner. The findings also reveal that organizational culture differences related to communication climate and internal control facilitates offshore IS project success. The social embeddedness perspective underscores the critical role of fine-grained information exchange between the client and vendor for feedback and learning. A climate of open communication on both sides should facilitate such transfer. Similarly, alignment of norms for internal control reduces conflicts around decision rights being tightly allocated or loosely managed. Thus, similarity between the client and vendor firm on these three cultural norms significantly aligns practices related to work processes, communication, and control, thereby reducing misunderstanding, conflict, and errors.

\section{Role of Project Leader Cultural Values}

We suggested that cultural factors are important in the IS offshoring context, not just at the macro level of differences in work practices between the two partnering firms, but also at the level of the project team. We suggested that project leader cultural values would influence the success of offshore IS projects. Our results provide only minimal support for this general relationship $\left(\Delta \mathrm{R}^{2}=.03\right)$, with only one project leader cultural value - namely, long-term orientation — being significant. However, our post hoc analysis examining projects without a client representative showed that project leader cultural values are indeed important. In the absence of a client representative as a steward of the client firm's interests, the project leader plays a critical role in the overall management and ultimate success of offshore IS projects. Specifically, our analysis of the 53 projects with no client representative revealed three project leader cultural valuesnamely, uncertainty avoidance, long-term orientation, and masculinity/feminity - had significant cross-level effects on cost overruns $\left(\Delta \mathrm{R}^{2}=.11\right)$ and client satisfaction $\left(\Delta \mathrm{R}^{2}=.12\right)$. In contrast, none of the project leader cultural characteristics was significant in the sample of 102 projects with a client representative.

\section{Role of Differences in Cultural Values Between Client Representative and Project Leader}

We suggested that cultural values also play an instrumental role in shaping the success of offshore IS projects that have a client representative on the team. In this case, consideration must be given to differences in cultural values between the client representative and project leader. Our results support this perspective, as the inclusion of project leader cultural values in addition to relational factors and differences in work 
practices factors did not explain any significant additional variance in success. In contrast, four of the five difference measures between the client representative and project leader on these espoused cultural values significantly relate to one or both measures of IS offshore project success. In fact, the inclusion of these cultural differences increased the explained variance by 13 percent for cost overruns and by 13 percent for client satisfaction over and above relational factors and work practice differences.

The findings suggest that differences between the client representative and project leader on uncertainty avoidance increased cost overruns and decreased client satisfaction. This difference is likely to result in lack of a shared mental model and possibly create conflict related to the extent of advanced planning to be undertaken, the rigidity with which plans need to be adhered, and the utility of day-to-day monitoring. Client representative-project leader differences on individualism/collectivism increased cost overruns and reduced client satisfaction. This difference is likely to surface in their disparate views on how team work is to be organized, managed, and rewarded. Differences between the client representative and project leader on long-term orientation increased cost overruns, but was not related to client satisfaction. This difference between client representative and project leader can lead to disagreements about outcomes and processes, and possibly the pursuit of misaligned actions. Finally, a disparity in masculinity/femininity did not lead to cost overruns but decreased client satisfaction. It likely creates disagreements on the implications of gender for the assignment of roles and responsibilities in projects.

\section{Strengths, Limitations, and Future Research}

Some positive features of the study lend credibility to the reported findings. We used multiple sources of data (i.e., survey data and archival project documents). Thus, concerns about common method variance are allayed. As noted earlier, we employed a total cost measure of development costs to compute cost overruns. The total cost considered expenses beyond billed man-hours. Additionally, the data were collected longitudinally, a positive feature of the study design. Finally, we focused on projects that required development of strategic solutions that are customized rather than those that require minor reconfiguration of previously developed modules. Such a focus leads us to insights that are applicable to contexts where the requirements expertise and systems development expertise that are distributed across onshore clients and offshore vendors must be integrated across cultural boundaries.
Just as there are positive aspects of the study, there are also limitations that should be acknowledged. For practical reasons, our study was limited to one vendor firm in India, which enabled us to test the hypotheses with a limited sample of projects relative to the number of variables. Also, we empirically tested the model only with data related to software development projects offshored from the United States to India. It is possible that some of the findings observed here are idiosyncratic to these contextual features. Future research should examine the extent to which our findings generalize to other types of offshoring projects and other countries (e.g., Japanese projects offshored to India; Japanese projects offshored to China). Within-country regional cultures may also be an important consideration for future research. A more complete understanding of offshoring requires additional multilevel studies that elaborate on the context of action and the interplay of institutions that operate in multiple social spaces (Avgerou 2002). Such studies will enable us to more fully understand how to integrate knowledge that is locally embedded (Nicholson and Sahay 2004). It is quite likely that the effects of team and organizational cultural factors would be relevant for onshore outsourced IS projects as well. While client-vendor cultural differences might be less pronounced in onshore outsourced IS projects, compared to offshored IS projects, the examination of the effects of such differences can help us better understand success in IS outsourcing.

In terms of client-vendor interactions, we considered two forms of face-to-face meetings: client representatives visiting the vendor and the vendor team visiting the client. We did not evaluate other forms of interaction, such as teleconferencing, phone calls, e-mails, and online chat sessions, for three reasons: some data were not captured by the vendor as it was complex to do so or was against company policy; some data that were captured were not archived by project; and some captured data were not shared with us for privacy and confidentiality reasons. Prior research points to the importance of communication media choice for effective team collaboration (Dennis et al. 2008; Maruping and Agarwal 2004). Thus, future research should evaluate the role of both face-to-face meetings and virtual interactions in offshore IS projects. More importantly, such research should attempt to capture the content of client-vendor interactions.

From the standpoint of cultural characteristics within offshore IS project teams, it will be important to understand the performance implications of teams composed of members from the same country liaising with a client representative also from the same country (Cox et al. 1991; Earley 1993; Watson et al. 1993). Attention could be devoted to surfacelevel (e.g., gender, age, race) and deep-level (e.g., person- 
ality) similarities among vendor team members, leader, client representative, and client liaison and their effects on cost overruns and client satisfaction (Harrison et al. 1998; Harrison et al. 2002). Other research on culture in teams suggests that the creation of hybrid cultures within teams may mitigate conflicts that result from cultural differences (e.g., Earley and Mosakowski 2000). A fine-grained view of trust would also yield insights into the effects of such hybrid cultures. Our study only examined client trust in the vendor and did not distinguish between benevolence, integrity, and ability based dimensions (Mayer et al. 1995). Building on such prior research, future research could investigate surfaceversus deep-level diversity and its effects on cost overruns vs. versus maintenance costs.

Our interest and emphasis was on two important outcomes related to projects: project cost overruns and client satisfaction. Other relevant outcomes should be studied. Team camaraderie is one such outcome (Hackman 1987). As team members will surely work on multiple projects together over time, it is important to understand the team structure and leader's cultural values that promote team camaraderie in the form of high team cohesion and satisfaction. In particular, it will be important to know if team structures and cultural values create suboptimal team camaraderie. While we examined project cost overruns by considering client and vendor expenses, we did not examine maintenance costs. Future research should evaluate the tension between cost overruns and maintenance costs associated with bugs and bug fixes. The focus on cost overruns is, of course, important. However, understanding the implications of such factors for maintenance costs in light of lower/higher cost overruns will help develop a more complete picture of offshore IS project success from the perspectives of the vendor and client. Future research should also examine value for money as an important outcome variable. Our measure of client satisfaction does not necessarily tap into this aspect of offshore IS project outcomes. Value for money may very well be linked to the tension between cost overruns and maintenance costs.

\section{Practical Implications}

The findings from this work have significant implications for the widely prevalent practice of offshoring IS projects from the United States to India. First, it is clear that while project characteristics and agency factors help contain cost overruns and increase client satisfaction, more can be done to improve these key outcomes. Based on our work, it is evident that firms wanting to leverage offshoring should create structures for jointly engaging in problem solving, establish mechanisms for fine-grained information transfer, and develop the trust of the client. They should strongly consider assigning a client representative to the project team and to undertake site visits to the vendor site. While these bridging initiatives require investments, they yield significant returns via reduced cost overruns and increased client satisfaction.

Second, firms entering into offshore agreements should proactively evaluate the work norms of the vendor relative to their own. They should especially examine if the vendor's practices - related to the organization of work, communications, and controls - are compatible with their practices. These practices, if misaligned, are likely to exacerbate coordination costs, lead to conflict, and hurt the progress and outcomes of these projects. To tackle potential problems that might arise from misalignment, client and vendor firms should strive to develop negotiated work cultures that give both parties a common base from which to operate (Earley and Mosakowski 2000; Krishna et al. 2004).

Third and finally, the client and vendor firm should determine key memberships on the project team. If a client representative is to be assigned, which we noted earlier as desirable, the differences in espoused cultural values between the representative and the project team leader should be assessed. Dissimilarities in cultural values should be minimized, as they create incompatibilities that are likely to surface in interaction and management style, assumptions made, and priorities that are pursued. Krishna et al. (2004) recommend the use of expatriates who can bridge cultures when such staffing decisions are made. However, if a client representative is not to be assigned, the espoused cultural values of the project leader should be considered. Those individuals with properties of high power distance and long-term orientation can enhance the likelihood of success of the project. However, caution should be taken in overemphasizing the uncertainty avoidance characteristic, as such project leaders may be intransigent on courses of action once plans have been formulated, even though some client members may find rigid adherence to plans appealing.

In sum, it is instructive to reinforce that the social embeddedness perspective enhances our understanding of cost overruns and client satisfaction in offshore IS projects, above and beyond what is explained by project characteristics and agency factors. This is particularly informative for practitioners, as our cost overruns measure considers billed manhours incurred by vendor team members and other expenses incurred by the client and the vendor, thus considering additional coordination costs incurred in offshore IS projects. Additionally, practitioners should benefit from understanding how relational factors can be used to enhance client satisfaction. 


\section{Conclusions}

We contribute to the IS offshoring literature by integrating multiple theoretical perspectives to understand how offshore IS projects should be successfully managed. Drawing on the social embeddedness literature, we identified three relational mechanisms - namely, client visits to the vendor site, client representation on the team, and open architectures for governance- as important predictors of offshore IS project success. Further, contingencies were identified relating to the influence of cultural factors - namely, differences in clientvendor firm work practices, project leader cultural values, and differences in cultural values between client representativeproject leader - on project success. Taken together, these findings contribute to the IS offshoring literature and extend the social embeddedness perspective. They demonstrate that an agency perspective is inadequate to manage offshore IS projects and that a holistic perspective that also focuses on relational mechanisms and cultural considerations is imperative. The findings have important implications for practice by providing guidance on how best to select the vendor, assign the leader and client representative, and design the team structure and client-vendor interaction to achieve project success.

\section{Acknowledgments}

The authors gratefully acknowledge the support of the vendor company, which has chosen to remain anonymous, in India for their generous support and access to data. The authors also thank S. Ram for his tireless help in supporting various aspects of the data gathering and organization phases. The authors thank the editors and reviewers at MIS Quarterly for their help and guidance to improve this paper. Finally, last but not least, our gratitude to Jan DeGross for her tireless efforts in getting this paper to its final form. Finally, we thank Jaime Newell for proofreading the paper.

\section{References}

Albrecth, A. J., and Gaffney, J. E. 1983. "Software Function, Source Lines of Code, and Development Effort Prediction: Software Science Validation," IEEE Transactions on Software Engineering (9:6), pp. 639-648.

Ancona, D. G., and Caldwell, D. F. 1992. "Demography and Design: Predictors of New Product Development Team Performance," Organization Science (3), pp. 321-341.

Ang, S., Slaughter, S., and Ng., K. Y. 2002. "Human Capital and Institutional Determinants of Information Technology Compensation: Modeling Multilevel and Cross-Level Interactions," Management Science (48:11), pp. 1427-1445.

Aulakh, P. S., Kotabe, M., and Sahay, A. 1996. "Trust and Performance in Cross-Border Marketing Partnerships: A Behavioral Approach," Journal of International Business Studies (27:5), pp. 1005-1032.
Avgerou, A. 2002. Information Systems and Global Diversity, Oxford, UK: Oxford University Press.

Banerjee, A. V., and Duflo, E. 2000. "Reputation Effects and the Limits of Contracting: A Study of the Indian Software Industry," Quarterly Journal of Economics (115:3), pp. 989-1017.

Bartunek, J. M., and Moch, M. K. 1987. "First-Order, SecondOrder, and Third-Order Change and Organizational Development Interventions: A Cognitive Approach," Journal of Applied Behavioral Science (23), pp. 483-500.

Berger, C. R. 1979. "Beyond Initial Understanding: Uncertainty, Understanding, and the Development of Interpersonal Relationships," in Language and Social Psychology, H. Giles and R. N. St. Clair (eds.), Oxford, UK: Blackwell, pp. 122-144.

Bertch, W. 2003. "How Offshoring Failed Us," Network Computing, October (http://www.networkcomputing.com/story/ singlePageFormat.jhtml;jsessionid=LZX3DXZCSO1U0QSND BGCKHQ? articleID=15201900; accessed August 26, 2006).

Blake, R. R., and Mouton, J. S. 1064. The Managerial Grid, Houston, TX: Gulf.

Bliese, P. D., and Hanges, P. J. 2004. "Being Both Too Liberal and Too Conservative: The Perils of Treating Grouped Data as Though They Were Independent," Organizational Research Methods (7:4), pp. 400-417.

Bliese, P. D., and Ployhart, R. E. 2002. "Growth Modeling Using Random Coefficient Models: Model Building, Testing, and Illustrations," Organizational Research Methods (5:4), pp. 362-387.

Bochner, S., and Hesketh, B. 1994. "Power Distance, Individualism/Collectivism, and Job-Related Attitudes in a Culturally Diverse Work Group," Journal of Cross-Cultural Psychology (25), pp. 233-257.

Bryk, A. S., and Raudenbush, S. W. 1992. Hierarchical Linear Models: Applications and Data Analysis Methods, Thousand Oaks, CA: Sage Publications.

Campion, M. A., Medsker, G. J., and Higgs, A. C. 1993. "Relations Between Work Group Characteristics and Effectiveness: Implications for Designing Effective Work Groups," Personnel Psychology (46), pp. 823-850.

Carmel, E., and Agarwal, R. 2002. "The Maturation of Offshore Sourcing of Information Technology Work," MIS Quarterly Executive (1:2), pp. 65-77.

Choudhury, V., and Sabherwal, R. 2003. "Portfolios of Control in Outsourced Software Development Projects," Information Systems Research (14:3), pp. 291-314.

Cox, T. H., Lobel, S. A., and McLeod, P. L. 1991. "Effects of Ethnic Group Cultural Differences on Cooperative and Competitive Behavior on a Group Task," Academy of Management Journal (34:4), pp. 827-847.

Dennis, A. R., Fuller, R. M., and Valacich, J. S. 2008. "Media, Tasks, and Communication Processes: A Theory of Media Synchronicity," MIS Quarterly (32:3), pp. 575-600.

Dyer, J. H., and Singh, H. 1998. "The Relational View: Cooperative Strategy and Sources of Interorganizational Competitive Advantage," Academy of Management Review (23:4), pp. 660-679. 
Earley, P. C. 1989. "Social Loafing and Collectivism," Administrative Science Quarterly (34), pp. 565-581.

Earley, P. C. 1993. "East Meets West Meets Mideast: Further Explorations of Collectivistic and Individualistic Work Groups," Academy of Management Journal (36), pp. 319-348.

Earley, P. C., and Mosakowski, E. 2000. "Creating Hybrid Team Cultures: An Empirical Test of Transnational Team Functioning," Academy of Management Journal (43:1), pp. 26-49.

Earley, P. C., and Stubblebine, P. 1989. "Multi-Cultural Examination of Performance Feedback," Group and Organization Studies (14), pp. 161-181.

Eisenhardt, K. M. 1985. "Control: Organizational and Economic Approaches," Management Science (31:2), pp. 134-149.

Faraj, S., and Sproull, L. 2000. "Coordinating Expertise in Software Development Teams,” Management Science (46:12), pp. 1554-1568.

Friedman, T. L. 2005. The World Is Flat: A Brief History of the Twenty-First Century, New York: Farrar, Straus and Giroux.

Gomez, C. B., Kirkman, B. L., and Shapiro, D. L. 2001. "The Impact of Collectivism and Ingroup/Outgroup Membership on the Evaluation of Generosity of Team Members," Academy of Management Journal (43), pp. 1097-1106.

Gopal, A., Mukhopadhyay, T., and Krishnan, M. S. 2002. "The Role of Communication and Processes in Offshore Software Development," Communications of the ACM (45:4), pp. 193-200.

Gopal, A., Sivaramakrishnan, K., Krishnan, M. S., and Mukhopadhyay, T. 2003. "Contracts in Offshore Software Development: An Empirical Analysis," Management Science (49:12), pp. 1671-1683.

Granovetter, M. 1985. "Economic Action and Social Structure: The Problem of Embeddedness," American Journal of Sociology (91:3), pp. 481-510.

Guinan, P. J., Cooprider, J. G., and Faraj, S. 1998. "Enabling Software Development Team Performance During Requirements Definition: A Behavioral Versus Technical Approach," Information Systems Research (9:2), pp. 101-125.

Hackman, J. R. 1987. "The Design of Work Teams," in Handbook of Organizational Behavior, J. Lorsch (ed.), Englewood Cliffs, NJ: Prentice-Hall, pp. 315-342.

Harris, S. G. 1994. "Organizational Culture and Individual Sensemaking: A Schema-Based Perspective," Organization Science (5), pp. 309-321.

Harrison, D. A., Price, K. H., and Bell, M. P. 1998. "Beyond Relational Demography: Time and the Effects of Surface- and Deep-Level Diversity on Work Group Cohesion," Academy of Management Journal (41:1), pp. 96-107.

Harrison, D. A., Price, K. H., Gavin, J. H., and Florey, A. T. 2002. "Time, Teams, and Task Performance: Changing Effects of Surface- and Deep-Level Diversity on Group Functioning," Academy of Management Journal (45:5), pp. 1029-1045.

Hartwick, J., and Barki, H. 1994. "Explaining the Role of User Participation in Information System Use," Management Science (40:4), pp. 440-465.

Hofmann, D. A. 1997. "An Overview of the Logic and Rationale of Hierarchical Linear Models," Journal of Management (23:6), pp. 723-744.
Hofstede, G. 1980. Culture's Consequences: International Differences in Work Related Values, Beverly Hills, CA: Sage Publications.

Hofstede, G. 2001. Culture's Consequences: Comparing Values, Behaviors, Institutions, and Organizations Across Nations, Thousand Oaks, CA: Sage Publications.

Hofstede, G. 2007. "Geert Hofsede ${ }^{\mathrm{TM}}$ Cultural Dimensions" (www.geert-hofstede.com; accessed March 23, 2007).

Hofstede, G., Neuijen, B., Ohayv, D. D., and Sanders, G. 1990. "Measuring Organizational Cultures: A Qualitative and Quantitative Study Across Twenty Cases," Administrative Science Quarterly (35), pp. 286-316.

Hunton, J. E., and Beeler, J. D. 1997. "Effects of User Participation in Systems Development: A Longitudinal Field Experiment," MIS Quarterly (21:4), pp. 359-388.

Inkpen, A. C., and Tsang, E. W. K. 2005. "Social Capital, Networks, and Knowledge Transfer," Academy of Management Review (30:1), pp. 146-165.

Ives, B., and Olson, M. H. 1984. "User Involvement and MIS Success: A Review of Research,” Management Science (30:5), pp. 586-603.

Jensen, M., and Meckling, W. 1976. "Theory of the Firm: Managerial Behavior, Agency Costs, and Ownership Structure," Journal of Financial Economics (3), pp. 305-360.

Johns, G. 2006. "The Essential Impact of Context on Organizational Behavior," Academy of Management Review (31:2), pp. 386-408.

Kaiser, K. M., and Hawk, S. 2004. "Evolution of Offshore Software Development: From Outsourcing to Cosourcing," MIS Quarterly Executive (3:2), pp. 69-81.

Kahneman, D., and Tversky, A. 1982. "The Simulation Heuristic," in Judgment Under Uncertainty: Heuristics and Biases, D. Kahneman, P. Slovic, and A. Tversky (eds.), New York: Cambridge University Press, pp. 201-208.

Keil, M., Mann, J., and Rai, A. 2000. "Why Software Projects Escalate: An Empirical Analysis and Test of Four Theoretical Models," MIS Quarterly (24:4), pp. 631-664.

Kenny, D. A., and Judd, C. M. 1986. "Consequences of Violating the Independence Assumption in Analysis of Variance," Psychological Bulletin (99), pp. 422-431.

Kirsch, L. J. 1997. "Portfolios of Control Modes and IS Project Management," Information Systems Research (8:3), pp. 215-239.

Kirsch, L. J., Sambamurthy, V., Ko, D., and Purvis, R. L. 2002. "Controlling Information Systems Development Projects: The View from the Client," Management Science (48:4), pp. 484-498.

Klein, K. J., Bliese, P. D., Kozlowski, S. W. J., Dansereau, F., Gavin, M. B., Griffin, M. A., Hoffman, D. A., James, L. R., Yammarino, F. J., and Bligh, M. C. 2000. "Multilevel Analytical Techniques: Commonalities, Differences and Continuing Questions," in Multilevel Theory, Research, and Methods in Organizations: Foundations, Extensions, and New Directions, K. J. Klein and S. W. J. Kozlowski (eds.), San Francisco: Jossey-Bass, pp. 512-553.

Klein, K. J., and Kozlowski, S. W. J. 2000. "From Micro to Meso: Critical Steps in Conceptualizing and Conducting Multi-Level Research," Organizational Research Methods (3), pp. 211-236. 
Klein, R., Rai, A., and Straub, D. 2007. "Competitive and Cooperative Domains in Supply Chain Logistics Relationships," Decision Sciences, (38:4), 611-646.

Koh, C., Ang, S., and Straub, D. W. 2004. "IT Outsourcing Success: A Psychological Contract Perspective," Information Systems Research (15:4), pp. 356-373.

Krishna, S., Sahay, S., and Walsham, G. 2004. "Managing CrossCultural Issues in Global Software Outsourcing," Communications of the ACM (47:4), pp. 62-66.

Lacity, M. C., and Willcocks, L. P. 1998. “An Empirical Investigation of Information Technology Sourcing Practices: Lessons from Experience," MIS Quarterly (22:3), pp. 363-408.

Lau, D., and Murnighan, K. 1998. "Demographic Diversity and Faultlines: The Compositional Dynamics of Organizational Groups," Academy of Management Review (23), pp. 325-340.

Lee, J-N., Miranda, S. M., and Kim Y-M. 2004. "IT Outsourcing Strategies: Universalistic, Contingency, and Configurational Explanations of Success," Information Systems Research (15:2), pp. 110-131.

Lewis, M., and Rai, A. 2006. "Four Ways to Build Sustainable Partnerships," MIT Supply Chain Strategy (2:7), pp. 9-10.

MacNeil, I. R. 1983. "Relational Contract: What We Know and Do Not Know," Wisconsin Law Review (4), pp. 483-525.

Maruping, L. M., and Agarwal, R. 2004. "Managing Team Interpersonal Processes Through Technology: A Task-Technology Fit Perspective," Journal of Applied Psychology (89:6), pp. 975-990.

Mathieu, J. E., Heffner, T. S., Goodwin, G. F., Salas, E., and Cannon-Bowers, J. A. 2000. "The Influence of Shared Mental Models on Team Process and Performance," Journal of Applied Psychology (85:2), pp. 273-283.

Mayer, G., Davis, J., and Schoorman, F. 1995. “An Integrative Model of Organizational Trust," Academy of Management Review (20:3), pp. 709-734.

Mitchell, V. 2006. "Knowledge Integration and Information Technology Project Performance," MIS Quarterly (30:4), pp. 919-939.

Mukhopadhyay, T., Vicinanza, S. S., and Prietula, M. J. 1992. "Examining the Feasibility of a Case-based Reasoning Model for Software Estimation," MIS Quarterly (16:2), pp. 155-171.

Nagarajan, A., and Mitchell, W. 1998. "Evolutionary Diffusion: Internal and External Methods Used to Acquire Encompassing, Complementary, and Incremental Technological Changes in the Lithotripsy Industry," Strategic Management Journal (19:11), pp. 1063-1077.

Nicholson, B., and Sahay, S. 2004. "Embeddedness Knowledge and Offshore Software Development," Information and Organization (14), pp. 329-365.

Nidumolu, S. R. 1995. "The Effect of Coordination and Uncertainty on Software Project Performance: Residual Performance Risk as an Intervening Variable," Information Systems Research (6:3), pp. 191-219.

Nidumolu, S. R., and Subramani, M. 2003. "The Matrix of Control: Combining Process and Structure Approaches to Managing Software Development," Journal of Management Information Systems (20), pp. 159-196.
Pothukuchi, V., Damanpour, F., Choi, J., Chen, C. C., and Park, S. H. 2002. "National and Organizational Culture Differences and International Joint Venture Performance," Journal of International Business Studies (33:2), pp. 243-265.

Putnam, L. L., and Poole, M. S. 1987. "Conflict and Negotiation," in Handbook of Organizational Communication, F. M. Jablin, L. L. Putnam, K. H. Roberts, and L. W. Porter (eds.), Newbury Park, CA: Sage Publications, pp. 549-599.

Ravichandran, R., and Rai, A. 2000. "Quality Management in Systems Development: An Organizational System Perspective," MIS Quarterly (24:3), pp. 381-415.

Redding, S., and Baldwin, E. 1991. Managers for Asia/Pacific: Recruitment and Development Strategies, Hong Kong: Business International.

Ribeiro, J. 2005. "India's Outsourcing Valued at \$60B by 2010," Computerworld, December 12 (http://www.computerworld. com/managementtopics/outsourcing/story/0,10801,107009,00. html? source $=$ NLT_XSP\&nid $=107009$; accessed August 26, 2006).

Ross, J., and Beath, C. 2006. "Sustainable IT Outsourcing Success: Let Enterprise Architecture Be Your Guide," MIS Quarterly Executive (5:4), pp. 181-192.

Sahay, S., Nicholson, B., and Krishna, S. 2003. Global IT Outsourcing, Cambridge, UK: Cambridge University Press.

Sedigh-Ali, S., Gafoor, A., and Paul, R. A. 2001. "Software Engineering Metrics for COTS-Based Systems," IEEE Computer (24:5), pp. 44-50.

Shackleton, V. J., and Ali, A. H. 1990. "Work-Related Values of Managers: A Test of the Hofstede Model," Journal of CrossCultural Psychology (21), pp. 109-118.

Srite, M., and Karahanna, E. 2006. "The Role of Espoused National Cultural Values in Technology Acceptance," MIS Quarterly (30:3), pp. 679-704.

Sully de Luque, M. F., and Sommer, S. M. 2000. "The Impact of Culture on Feedback-Seeking Behavior: An Integrated Model and Propositions," Academy of Management Review (25:4), pp. 829-849.

Thibodeau, P. 2005. "China Starts IT Services Push," Computerworld, August 12 (http://computerworld.com/ managementtopics/outsourcing/story/0,10801,103894,00.html; accessed August 26, 2006).

Uzzi, B. 1996. "The Sources and Consequences of Embeddedness for the Economic Performance of Organizations: The Network Effect," American Sociological Review (61:4), pp. 674-698.

Uzzi, B. 1997. "Social Structure and Competition in Interfirm Networks: The Paradox of Embeddedness," Administrative Science Quarterly (42), pp. 35-67.

Uzzi, B., and Lancaster, R. 2003. "The Role of Interfirm Relationships in Interfirm Knowledge Transfer and Learning: The Case of Corporate Debt Markets," Management Science (49:4), pp. 383-399.

Wallace, L., Keil, M., and Rai, A. 2004. "How Software Project Risks Affect Project Outcomes: An Investigation of the Dimensions of Risks and an Exploratory Model," Decision Sciences (35:2), pp. 289-321. 
Walsham, G. 2002. "Cross-Cultural Software Production and Use: A Structurational Analysis,” MIS Quarterly (26:4), pp. 359-380.

Watson, W. E., Kumar, K., and Michaelsen, L. K. 1993. "Cultural Diversity's Impact on Interaction Processes and Performance: Comparing Homogeneous and Diverse Task Groups," Academy of Management Journal (36:3), pp. 590-602.

\section{About the Authors}

Arun Rai is Regents' Professor and the Harkins Chair in the Center for Process Innovation and the Department of Computer Information Systems at the Robinson College of Business, Georgia State University. His research focuses on understanding interorganizational relationships and IT-enabled innovation. His articles have appeared in Management Science, MIS Quarterly, Decision Sciences, European Journal of Operations Research, IEEE Transactions on Engineering Management, Information Systems Research, Journal of Management Information Systems, and other journals. He serves as a senior editor at Information Systems Research and as an associate editor at Journal of MIS. He has also served as a senior editor at Journal of Strategic Information Systems and as an associate editor at Management Science and MIS Quarterly. His research has been sponsored by leading corporations, including A. T. Kearney, Bozell Worldwide, Daimler-Chrysler, Deutsche Bank, Gartner, Georgia-Pacific, IBM, Intel, UPS, SAP, and SunTrust.

Likoebe M. Maruping is an assistant professor of Information Systems in the Sam M. Walton College of Business at the University of Arkansas. Likoebe's research is primarily focused on the activities through which software development teams improve software project outcomes. His current work in this area focuses on understanding how teams cope with uncertainty in software development projects. He also enjoys conducting research on virtual teams and the implementation of new technologies in organizations. His research has been published or is forthcoming in premier information systems, organizational behavior, and psychology journals including MIS Quarterly, Information Systems Research, Organization Science, Journal of Applied Psychology, and Organizational Behavior and Human Decision Processes.

Viswanath Venkatesh, who completed his Ph.D. at the University of Minnesota in 1997, is a professor and Billingsley Chair in Information Systems at the Walton College of Business, University of Arkansas. His research focuses on understanding the diffusion of technologies in organizations and society. His work has appeared and is forthcoming in leading information systems, organizational behavior, operations management, marketing, and psychology journals. His articles have been cited about 7,000 times per Google Scholar and about 3,000 times per Web of Science. Some of his papers published in various journals (Decision Sciences 1996, Information Systems Research 2000, Management Science 2000 and MIS Quarterly 2003) are among the most cited papers published in the respective journals. He currently serves as a senior editor at Information Systems Research and as an associate editor at Decision Sciences Journal, and has served as an associate editor at MIS Quarterly and Management Science. 


\section{OfFSHORE INFORMATION SYSTEMS PROJECT SUCCESS: THE ROLE OF SOCIAL EMBEDDEDNESS AND CULTURAL CHARACTERISTICS}

By: Arun Rai

Robinson College of Business

Georgia State University

Atlanta, GA 30303

U.S.A.

arunrai@gsu.edu

Likoebe M. Maruping

Walton College of Business

University of Arkansas

Fayetteville, AR 72701

U.S.A.

Imaruping@walton.uark.edu

\author{
Viswanath Venkatesh \\ Walton College of Business \\ University of Arkansas \\ Fayetteville, AR 72701 \\ U.S.A. \\ vvenkatesh@vvenkatesh.us
}

\section{Appendix A}

\section{Project Illustration}

\section{Background of the Offshore Project}

The offshore vendor firm in India was contracted by a client firm in the United States, which operates in the automobile sector, to develop a multiuser decision support system. The client firm had not previously contracted the services of the offshore vendor. The system being developed was of strategic importance to the customer as its core business processes related to planning and management of vendors were enabled by this information system. Given the strategic nature of the project, the project complexity was high, based on an assessment of use cases and adjusted function points. The project was budgeted for nearly 150,000 man hours of development time and was projected to take about four months to complete with 30 consultants and analysts assigned to the project. To accommodate for the requirements uncertainty, a total of 20 formal written changes were made to the contract.

In terms of project outcomes, there was a total cost overrun of 15 percent for billed man-hours for the development effort; and 22 percent additional expenditures incurred by the client above and beyond the negotiated billed expenses for specialized software, training, conferences, and visits to sites of customers or partners of the client firm. The project took a little under five months to complete. The client satisfaction, 
measured four months after the completion of the project, was 3.8 on a scale of 1 to 7.

\section{Contractual Characteristics}

The project was monitored using a moderate level of detail for SLAs that were specified in the contract. Examples of these SLAs included budgeted versus actual man hours and monthly reporting. In addition, the contract type is best described as one focused on time and materials.

\section{Relational Exchange Characteristics}

The client firm's score for trust in the vendor was 4.2 on the 1 to 7 scale. To facilitate coordination, a client representative of U.S. origin was assigned by the client firm to the project, and spent 20 percent of his time at the site in India. To facilitate discussions on critical issues and information exchange, the client visited the project team two times. During the project, an average of three project team members visited the client site two times.

\section{Vendor-Client Firm Work Practices Differences}

Based on the three-item scales for each of the six dimensions of organizational work practices, the scores for the client and vendor firm are shown below.

\begin{tabular}{|l|c|c|}
\hline \multicolumn{1}{|c|}{ Work Practices Norms } & Client & Vendor \\
\hline Process versus result orientation & 4.1 & 5.2 \\
\hline Employee versus job orientation & 4.4 & 4.7 \\
\hline Parochialism versus professionalism & 3.8 & 3.9 \\
\hline Open versus closed system & 4.7 & 3.9 \\
\hline Loose versus tight control & 5.0 & 5.2 \\
\hline Normative versus pragmatic orientation & 4.0 & 5.1 \\
\hline
\end{tabular}

As can be seen, the firms are quite similar with respect to three of the six practices. The largest differences were in the areas of process versus result orientation, open versus closed system, and normative versus pragmatic orientation.

\section{Project Leader Cultural Values and Differences with Client Representative}

A female project leader was assigned to manage the project. The project leader had significant project management experience, having managed 12 completed projects prior to this engagement. The cultural values of the project leader and the client representative, and their differences, based on Hofstede's 100-point scale — as specified in the VSM 94 manual-are shown below.

\begin{tabular}{|l|c|c|}
\hline \multicolumn{1}{|c|}{ Espoused Cultural Values } & $\begin{array}{c}\text { Project } \\
\text { Leader }\end{array}$ & $\begin{array}{c}\text { Client } \\
\text { Representative }\end{array}$ \\
\hline Uncertainty avoidance & 42 & 64 \\
\hline Long-term orientation & 64 & 29 \\
\hline Power distance & 52 & 46 \\
\hline Individualism/collectivism & 44 & 80 \\
\hline Masculinity/femininity & 55 & 60 \\
\hline
\end{tabular}

As can be seen, the project leader and the client representative are quite similar with respect to two of the five values. The largest differences between them are in the areas of uncertainty avoidance, long-term orientation, and individualism/collectivism. 


\section{Appendix B}

\section{Scales}

Organizational Work Practices (Hofstede et al. 1990); 100-point scale (e.g., $0=$ process-oriented; $100=$ result-oriented) — the score for each practice is the average of the response to each of the three items.

Process-oriented versus Result-oriented

1. Comfortable in unfamiliar situations.

2. Each day brings new challenges.

3. People put in maximal effort.

Employee-oriented versus Job-oriented

1. Important decisions made by individuals.

2. Organization only interested in work people do.

2. Little concern for personal problems of employees.

Parochial versus Professional

1. People's private life is their own business.

2. Job competence is only criterion in hiring people.

3. Think three years ahead or more.

Open System versus Closed System

1. Only very special people fit in organization.

2. Organization and people closed and secretive.

3. New employees need more than a year to feel at home.

Loose Control versus Tight Control

1. Everybody cost-conscious.

2. Meeting times kept punctually.

3. Always speak seriously of organization and job.

Normative versus Pragmatic

1. Pragmatic, not dogmatic in matters of ethics.

2. Major emphasis on meeting customer needs.

3. Results more important than procedures.

Interorganizational Trust (Aulakh et al. 1996); Anchors: $1=$ Strongly Disagree; $7=$ Strongly Agree.

1. Our business relationship with [vendor name] is characterized by high levels of trust.

2. Our firm and [vendor name] generally trust each other that each will stay within the terms of the contract.

3. We and [vendor name] are generally skeptical of the information provided to each other. (reverse coded)

Client Satisfaction (Nidumolu 1995); Anchors: 1 = Very Poor; 7 = Very Good.

1. Ease of use of software.

2. Ability to customize outputs to various user needs.

3. Range of outputs that can be generated.

4. Overall responsiveness of software to users.

Espoused Cultural Values (Hofstede's VSM94); 100-point scale

Calculations:

Note that, mathematically, it is possible for the values to be below 0 and above 100 .

Uncertainty avoidance $=25($ item 1$)+20($ item 2$)-50($ item 3$)-15($ item 4$)+120$

Long-term orientation $=45($ item 1$)-30($ item 2$)-35($ item 3$)+15($ item 4$)+67$ 
Power distance $=-35($ item 1$)+35($ item 2$)+25($ item 3$)-20($ item 4$)-20$

Individualism $=-50($ item 1$)+30($ item 2$)+20($ item 3$)-25($ item 4$)+130$

Masculinity $=60($ item 1$)-20($ item 2$)+20($ item 3$)-70($ item 4$)+100$

${ }^{\mathrm{a}}$ Measured on a 5 -point Likert scale: $1=$ very seldom; $5=$ very frequently.

${ }^{\mathrm{b}}$ Measured on a 5-point Likert scale: $1=$ strongly disagree; $5=$ strongly agree.

${ }^{\mathrm{c}}$ Measured on a 5-point Likert scale: $1=$ of utmost importance; $5=$ of very little or no importance.

${ }^{\mathrm{d}}$ Measured on a 5 -point Likert scale: $1=$ never; 5 = always.

Uncertainty Avoidance $(0=$ weak uncertainty avoidance $; 100=$ strong uncertainty avoidance $)$

1. How often do you feel nervous at work? ${ }^{\mathrm{a}}$

2. One can be a good manager without having precise answers to most questions that subordinates may raise about their work. ${ }^{\mathrm{b}}$

3. Competition between employees usually does more harm than good. ${ }^{\mathrm{b}}$

4. A company's or organization's rules should not be broken — not even when the employee thinks it is in the company's best interest. ${ }^{b}$

Long-term Orientation ( $0=$ very short-term oriented; $100=$ very long-term oriented)

In your private life, how important is each of the following to you?

1. Personal steadiness and stability. ${ }^{\mathrm{c}}$

2. Thrift. $^{\mathrm{c}}$

3. Persistence (perseverance). ${ }^{\mathrm{c}}$

4. Respect for tradition. ${ }^{c}$

Power Distance $(0=$ small power distance; $100=$ large power distance)

1. In your job, how important would it be to you to have a good working relationship with your direct superior?

2. In your job, how important would it be to you to be consulted by your direct superior in his/her decisions?

3. In your experience, how frequently are subordinates afraid to express disagreement with their superiors? ${ }^{\mathrm{d}}$

4. An organization's structure in which certain subordinates have two bosses should be avoided at all costs. ${ }^{\text {b }}$

Individualism/collectivism ( $0=$ strongly collectivist; $100=$ strongly individualist $)$

1. In your job, how important would it be to you to have sufficient time for your personal or family life?

2. In your job, how important would it be to you to have good physical working conditions? ${ }^{\mathrm{c}}$

3. In your job, how important would it be to you to have security of employment? ${ }^{c}$

4. In your job, how important would it be to you to have an element of variety and adventure in the job?

Masculinity/femininity ( 0 = strongly feminine; $100=$ strongly masculine $)$

1. In your job, how important would it be to you to work well with people who cooperate well with one another? ${ }^{\mathrm{c}}$

2. In your job, how important would it be to you to have an opportunity for advancement to higher level jobs?

3. Most people can be trusted. ${ }^{\mathrm{b}}$

4. When people have failed in life it is often their own fault. ${ }^{b}$

\section{Appendix C}

\section{Equations}

The dependent variables — cost overruns ${ }_{\mathrm{ij}}$ and client satisfaction $\mathrm{i}_{\mathrm{ij}}$-represent the outcomes for project $i$ under project leader $j$. The intercepts are estimated separately for each project leader as indicated by the subscript $j$ for each beta coefficient $(\beta)$. The level-1 residual is noted by $r_{i j}$ (Bryk and Raudenbush 1992; Hofmann 1997). The gamma coefficients ( $\mathrm{Y}$ ) are similar to beta coefficients, except that they are at level-2 and are estimated using a generalized least squares (GLS) approach (Bryk and Raudenbush 1992). Finally, $U_{0 j}$ is a level-2 residual. As the equations below indicate, $\beta_{0 j}$, was allowed to randomly vary so that we could test the crosslevel main effects.

The equations for the results presented in Table 4 are outlined below. Note that the equations used to predict cost overruns and client satisfaction are the same. In the interest of brevity, we present the equations for cost overruns. 


\section{Model 1}

Level-1:

Cost overruns $_{\mathrm{ij}}=\beta_{0 \mathrm{j}}+\beta_{1 \mathrm{j}}$ Project complexity $+\beta_{2 \mathrm{j}}$ Requirements uncertainty $+\beta_{3 \mathrm{j}}$ Project size $+\beta_{4 \mathrm{j}}$ Service level agreements $+\beta_{5 \mathrm{j}}$ Risk sharing $+r_{i j}$

Level-2:

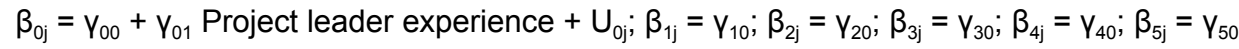

\section{Model 2}

Level-1:

Cost overruns $_{\mathrm{ij}}=\beta_{0 \mathrm{j}}+\beta_{1 \mathrm{j}}$ Project complexity $+\beta_{2 \mathrm{j}}$ Requirements uncertainty $+\beta_{3 \mathrm{j}}$ Project size $+\beta_{4 \mathrm{j}}$ Service level agreements $+\beta_{5 \mathrm{j}}$ Risk sharing $+\beta_{6 \mathrm{j}}$ Firm history $+\beta_{7 \mathrm{j}}$ Trust $+\beta_{8 \mathrm{j}}$ Clientmeet $+\beta_{9 \mathrm{j}}$ Teammeet $+\beta_{10 \mathrm{j}}$ Client representative $+\mathrm{r}_{\mathrm{ij}}$

Level-2:

$\beta_{0 \mathrm{j}}=v_{00}+\mathrm{v}_{01}$ Project leader experience $+\mathrm{U}_{0 \mathrm{j}} ; \beta_{1 \mathrm{j}}=\mathrm{v}_{10} ; \beta_{2 \mathrm{j}}=\mathrm{v}_{20} ; \beta_{3 \mathrm{j}}=\mathrm{v}_{30} ; \beta_{4 \mathrm{j}}=\mathrm{v}_{40} ; \beta_{5 \mathrm{j}}=\mathrm{v}_{50} ; \beta_{6 \mathrm{j}}=\mathrm{v}_{60} ; \beta_{7 \mathrm{j}}=\mathrm{v}_{70} ; \beta_{8 \mathrm{j}}=\mathrm{v}_{80} ; \beta_{9 \mathrm{j}}=\mathrm{v}_{90} ; \beta_{10 \mathrm{j}}$ $=Y_{100}$

\section{Model 3}

Level-1:

Cost overruns $_{\mathrm{ij}}=\beta_{0 \mathrm{j}}+\beta_{1 \mathrm{j}}$ Project complexity $+\beta_{2 \mathrm{j}}$ Requirements uncertainty $+\beta_{3 \mathrm{j}}$ Project size $+\beta_{4 \mathrm{j}}$ Service level agreements $+\beta_{5 \mathrm{j}}$ Risk sharing $+\beta_{6 \mathrm{j}}$ Firm history $+\beta_{7 \mathrm{j}}$ Trust $+\beta_{8 \mathrm{j}}$ Clientmeet $+\beta_{9 \mathrm{j}}$ Teammeet $+\beta_{10 \mathrm{j}}$ Client representative $+\beta_{11 \mathrm{j}} \Delta$ Process $+\beta_{12 \mathrm{j}}$ $\Delta$ Employee $+\beta_{13 \mathrm{j}} \Delta$ Parochial $+\beta_{14 \mathrm{j}} \Delta$ Open $+\beta_{15 \mathrm{j}} \Delta$ Loose $+\beta_{16 \mathrm{j}} \Delta$ Normative $+\mathrm{r}_{\mathrm{ij}}$

Level-2:

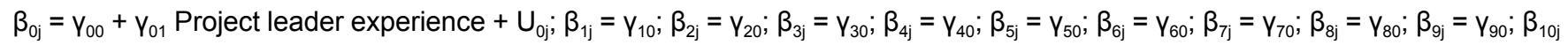
$=\mathrm{v}_{100} ; \beta_{11 \mathrm{j}}=\mathrm{v}_{110} ; \beta_{12 \mathrm{j}}=\mathrm{\gamma}_{120} ; \beta_{13 \mathrm{j}}=\mathrm{v}_{130} ; \beta_{14 \mathrm{j}}=\mathrm{\gamma}_{140} ; \beta_{15 \mathrm{j}}=\mathrm{v}_{150} ; \beta_{16 \mathrm{j}}=\mathrm{\gamma}_{160}$

\section{Model 4}

Level-1:

Cost overruns $_{i j}=\beta_{0 j}+\beta_{1 j}$ Project complexity $+\beta_{2 j}$ Requirements uncertainty $+\beta_{3 j}$ Project size $+\beta_{4 j}$ Service level agreements $+\beta_{5 j}$ Risk sharing $+\beta_{6 j}$ Firm history $+\beta_{7 j}$ Trust $+\beta_{8 j}$ Clientmeet $+\beta_{9 j}$ Teammeet $+\beta_{10 j}$ Client representation $+\beta_{11 j}$ Process $+\beta_{12 \mathrm{j}}$ $\Delta$ Employee $+\beta_{13 \mathrm{j}} \Delta$ Parochial $+\beta_{14 \mathrm{j}} \Delta$ Open $+\beta_{15 \mathrm{j}} \Delta$ Loose $+\beta_{16 \mathrm{j}} \Delta$ Normative $+\mathrm{r}_{\mathrm{ij}}$

\section{Level-2:}

$\beta_{0 j}=\gamma_{00}+\gamma_{01}$ Project leader experience $+\gamma_{02}$ Uncertainty avoidance $+\gamma_{03}$ Long-term orientation $+\gamma_{04}$ Power distance $+\gamma_{05}$ Masculinity $+\gamma_{06}$ Individualism $+U_{0 j} ; \beta_{1 j}=v_{10} ; \beta_{2 j}=v_{20} ; \beta_{3 j}=v_{30} ; \beta_{4 j}=v_{40} ; \beta_{5 j}=v_{50} ; \beta_{6 j}=v_{60} ; \beta_{7 j}=v_{70} ; \beta_{8 j}=v_{80} ; \beta_{9 j}=v_{90} ; \beta_{10 j}=\gamma_{100} ; \beta_{11 j}$ $=\gamma_{110} ; \beta_{12 \mathrm{j}}=\mathrm{V}_{120} ; \beta_{13 \mathrm{j}}=\mathrm{V}_{130} ; \beta_{14 \mathrm{j}}=\mathrm{V}_{140} ; \beta_{15 \mathrm{j}}=\mathrm{V}_{150} ; \beta_{16 \mathrm{j}}=\mathrm{V}_{160}$

The equations for the results presented in Table 5 are outlined below. Note that the equations used to predict cost overruns and client satisfaction are the same. In the interest of brevity, we present the equations for cost overruns.

\section{Model 1}

Level-1:

Cost overruns $_{\mathrm{ij}}=\beta_{0 \mathrm{j}}+\beta_{1 \mathrm{j}}$ Project complexity $+\beta_{2 \mathrm{j}}$ Requirements uncertainty $+\beta_{3 \mathrm{j}}$ Project size $+\beta_{4 \mathrm{j}}$ Service level agreements $+\beta_{5 \mathrm{j}}$ Risk sharing $+r_{i j}$

Level-2:

$\beta_{0 \mathrm{j}}=\mathrm{V}_{00}+\mathrm{V}_{01}$ Project leader experience $+\mathrm{U}_{0 \mathrm{j}} ; \beta_{1 \mathrm{j}}=\mathrm{V}_{10} ; \beta_{2 \mathrm{j}}=\mathrm{V}_{20} ; \beta_{3 \mathrm{j}}=\mathrm{V}_{30} ; \beta_{4 \mathrm{j}}=\mathrm{V}_{40} ; \beta_{5 \mathrm{j}}=\mathrm{V}_{50}$

\section{Model 2}

Level-1:

Cost overruns $_{\mathrm{ij}}=\beta_{0 \mathrm{j}}+\beta_{1 \mathrm{j}}$ Project complexity $+\beta_{2 \mathrm{j}}$ Requirements uncertainty $+\beta_{3 \mathrm{j}}$ Project size $+\beta_{4 \mathrm{j}}$ Service level agreements $+\beta_{5 \mathrm{j}}$ Risk sharing $+\beta_{6 \mathrm{j}}$ Firm history $+\beta_{7 \mathrm{j}}$ Trust $+\beta_{8 \mathrm{j}}$ Clientmeet $+\beta_{9 \mathrm{j}}$ Teammeet $+\beta_{10 \mathrm{j}} \Delta$ Process $+\beta_{11 \mathrm{j}} \Delta$ Employee $+\beta_{12 \mathrm{j}} \Delta$ Parochial + $\beta_{13 \mathrm{j}} \Delta$ Open $+\beta_{14 \mathrm{j}} \Delta$ Loose $+\beta_{15 \mathrm{j}} \Delta$ Normative $+\mathrm{r}_{\mathrm{ij}}$ 
Level-2:

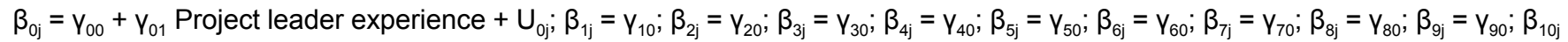
$=\gamma_{100} ; \beta_{11 \mathrm{j}}=\mathrm{\gamma}_{110} ; \beta_{12 \mathrm{j}}=\mathrm{\gamma}_{120} ; \beta_{13 \mathrm{j}}=\mathrm{\gamma}_{130} ; \beta_{14 \mathrm{j}}=\mathrm{\gamma}_{140} ; \beta_{15 \mathrm{j}}=\mathrm{\gamma}_{150}$

\section{Model 3}

Level-1:

Cost overruns $_{\mathrm{ij}}=\beta_{0 \mathrm{j}}+\beta_{1 \mathrm{j}}$ Project complexity $+\beta_{2 \mathrm{j}}$ Requirements uncertainty $+\beta_{3 \mathrm{j}}$ Project size $+\beta_{4 \mathrm{j}}$ Service level agreements $+\beta_{5 \mathrm{j}}$ Risk sharing $+\beta_{6 \mathrm{j}}$ Firm history $+\beta_{7 \mathrm{j}}$ Trust $+\beta_{8 \mathrm{j}}$ Clientmeet $+\beta_{9 \mathrm{j}}$ Teammeet $+\beta_{10 \mathrm{j}} \Delta$ Process $+\beta_{11 \mathrm{j}} \Delta$ Employee $+\beta_{12 \mathrm{j}} \Delta$ Parochial + $\beta_{13 \mathrm{j}} \Delta$ Open $+\beta_{14 \mathrm{j}} \Delta$ Loose $+\beta_{15 \mathrm{j}} \Delta$ Normative $+\mathrm{r}_{\mathrm{ij}}$

Level-2:

$\beta_{0 \mathrm{j}}=\mathrm{v}_{00}+\mathrm{v}_{01}$ Project leader experience $+\mathrm{U}_{0 \mathrm{j}} ; \beta_{1 \mathrm{j}}=\mathrm{v}_{10} ; \beta_{2 \mathrm{j}}=\mathrm{v}_{20} ; \beta_{3 \mathrm{j}}=\mathrm{v}_{30} ; \beta_{4 \mathrm{j}}=\mathrm{v}_{40} ; \beta_{5 \mathrm{j}}=\mathrm{v}_{50} ; \beta_{6 \mathrm{j}}=\mathrm{v}_{60} ; \beta_{7 \mathrm{j}}=\mathrm{v}_{70} ; \beta_{8 \mathrm{j}}=\mathrm{v}_{80} ; \beta_{9 \mathrm{j}}=\mathrm{v}_{90} ; \beta_{10 \mathrm{j}}$ $=\mathrm{Y}_{100} ; \beta_{11 \mathrm{j}}=\mathrm{Y}_{110} ; \beta_{12 \mathrm{j}}=\mathrm{Y}_{120} ; \beta_{13 \mathrm{j}}=\mathrm{Y}_{130} ; \beta_{14 \mathrm{j}}=\mathrm{Y}_{140} ; \beta_{15 \mathrm{j}}=\mathrm{Y}_{150}$

\section{Model 4}

Level-1:

Cost overruns $_{\mathrm{ij}}=\beta_{0 \mathrm{j}}+\beta_{1 \mathrm{j}}$ Project complexity $+\beta_{2 \mathrm{j}}$ Requirements uncertainty $+\beta_{3 \mathrm{j}}$ Project size $+\beta_{4 \mathrm{j}}$ Service level agreements $+\beta_{5 \mathrm{j}}$ Risk sharing $+\beta_{6 j}$ Firm history $+\beta_{7 j}$ Trust $+\beta_{8 j}$ Clientmeet $+\beta_{9 j}$ Teammeet $+\beta_{10 j} \Delta$ Process $+\beta_{11 j} \Delta$ Employee $+\beta_{12 \mathrm{j}} \Delta$ Parochial + $\beta_{13 \mathrm{j}} \Delta$ Open $+\beta_{14 \mathrm{j}} \Delta$ Loose $+\beta_{15 \mathrm{j}} \Delta$ Normative $+\beta_{16 \mathrm{j}} \Delta$ Uncertainty avoidance $+\beta_{17 \mathrm{j}} \Delta$ Long-term orientation $+\beta_{18 \mathrm{j}} \Delta$ Power distance + $\beta_{19 \mathrm{j}} \Delta$ Masculinity $+\beta_{20 \mathrm{j}} \Delta$ Individualism $+r_{\mathrm{ij}}$

Level-2:

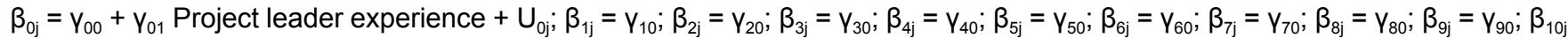

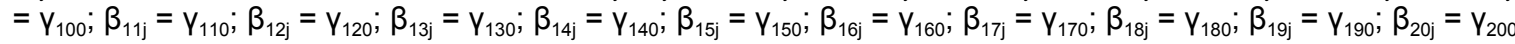

The equations for the results presented in Table 6 are outlined below. Note that the equations used to predict cost overruns and client satisfaction are the same. In the interest of brevity, we present the equations for cost overruns.

\section{Model 1}

Level-1:

Cost overruns $_{\mathrm{ij}}=\beta_{0 \mathrm{j}}+\beta_{1 \mathrm{j}}$ Project complexity $+\beta_{2 \mathrm{j}}$ Requirements uncertainty $+\beta_{3 \mathrm{j}}$ Project size $+\beta_{4 \mathrm{j}}$ Service level agreements $+\beta_{5 \mathrm{j}}$ Risk sharing $+r_{i j}$

Level-2:

$\beta_{0 j}=Y_{00}+Y_{01}$ Project leader experience $+U_{0 j} ; \beta_{1 j}=Y_{10} ; \beta_{2 j}=Y_{20} ; \beta_{3 j}=\gamma_{30} ; \beta_{4 j}=\gamma_{40} ; \beta_{5 j}=Y_{50}$

\section{Model 2}

Level-1:

Cost overruns $_{i j}=\beta_{0 j}+\beta_{1 j}$ Project complexity $+\beta_{2 j}$ Requirements uncertainty $+\beta_{3 j}$ Project size $+\beta_{4 j}$ Service level agreements $+\beta_{5 j}$ Risk sharing $+\beta_{6 \mathrm{j}}$ Firm history $+\beta_{7 \mathrm{j}}$ Trust $+\beta_{8 \mathrm{j}}$ Clientmeet $+\beta_{9 \mathrm{j}}$ Teammeet $+\beta_{10 \mathrm{j}} \Delta$ Process $+\beta_{11 \mathrm{j}} \Delta$ Employee $+\beta_{12 \mathrm{j}} \Delta$ Parochial + $\beta_{13 \mathrm{j}} \Delta$ Open $+\beta_{14 \mathrm{j}} \Delta$ Loose $+\beta_{15 \mathrm{j}} \Delta$ Normative $+\mathrm{r}_{\mathrm{ij}}$

Level-2:

$\beta_{0 \mathrm{j}}=\mathrm{v}_{00}+\mathrm{v}_{01}$ Project leader experience $+\mathrm{U}_{0 \mathrm{j}} ; \beta_{1 \mathrm{j}}=\mathrm{v}_{10} ; \beta_{2 \mathrm{j}}=\mathrm{v}_{20} ; \beta_{3 \mathrm{j}}=\mathrm{v}_{30} ; \beta_{4 \mathrm{j}}=\mathrm{v}_{40} ; \beta_{5 \mathrm{j}}=\mathrm{v}_{50} ; \beta_{6 \mathrm{j}}=\mathrm{v}_{60} ; \beta_{7 \mathrm{j}}=\mathrm{v}_{70} ; \beta_{8 \mathrm{j}}=\mathrm{v}_{80} ; \beta_{9 \mathrm{j}}=\mathrm{v}_{90} ; \beta_{10 \mathrm{j}}$ $=\mathrm{V}_{100} ; \beta_{11 \mathrm{j}}=\mathrm{V}_{110} ; \beta_{12 \mathrm{j}}=\mathrm{\gamma}_{120} ; \beta_{13 \mathrm{j}}=\mathrm{\gamma}_{130} ; \beta_{14 \mathrm{j}}=\mathrm{\gamma}_{140} ; \beta_{15 \mathrm{j}}=\mathrm{\gamma}_{150}$

\section{Model 3}

Level-1:

Cost overruns $_{\mathrm{ij}}=\beta_{0 \mathrm{j}}+\beta_{1 \mathrm{j}}$ Project complexity $+\beta_{2 \mathrm{j}}$ Requirements uncertainty $+\beta_{3 \mathrm{j}}$ Project size $+\beta_{4 \mathrm{j}}$ Service level agreements $+\beta_{5 \mathrm{j}}$ Risk sharing $+\beta_{6 \mathrm{j}}$ Firm history $+\beta_{7 \mathrm{j}}$ Trust $+\beta_{8 \mathrm{j}}$ Clientmeet $+\beta_{9 \mathrm{j}}$ Teammeet $+\beta_{10 \mathrm{j}} \Delta$ Process $+\beta_{11 \mathrm{j}} \Delta$ Employee $+\beta_{12 \mathrm{j}} \Delta$ Parochial + $\beta_{13 \mathrm{j}} \Delta$ Open $+\beta_{14 \mathrm{j}} \Delta$ Loose $+\beta_{15 \mathrm{j}} \Delta$ Normative $+\mathrm{r}_{\mathrm{ij}}$

Level-2:

$\beta_{0 j}=Y_{00}+Y_{01}$ Project leader experience $+Y_{02}$ Uncertainty avoidance $+Y_{03}$ Long-term orientation $+Y_{04}$ Power distance $+Y_{05}$ Masculinity $+\gamma_{06}$ Individualism $+U_{0 j} ; \beta_{1 j}=\gamma_{10} ; \beta_{2 j}=\gamma_{20} ; \beta_{3 j}=v_{30} ; \beta_{4 j}=\gamma_{40} ; \beta_{5 j}=\gamma_{50} ; \beta_{6 j}=\gamma_{60} ; \beta_{7 j}=\gamma_{70} ; \beta_{8 j}=\gamma_{80} ; \beta_{9 j}=\gamma_{90} ; \beta_{10 j}=\gamma_{100} ; \beta_{11 j}$ $=\mathrm{V}_{110} ; \beta_{12 \mathrm{j}}=\mathrm{V}_{120} ; \beta_{13 \mathrm{j}}=\mathrm{V}_{130} ; \beta_{14 \mathrm{j}}=\mathrm{V}_{140} ; \beta_{15 \mathrm{j}}=\mathrm{V}_{150}$ 

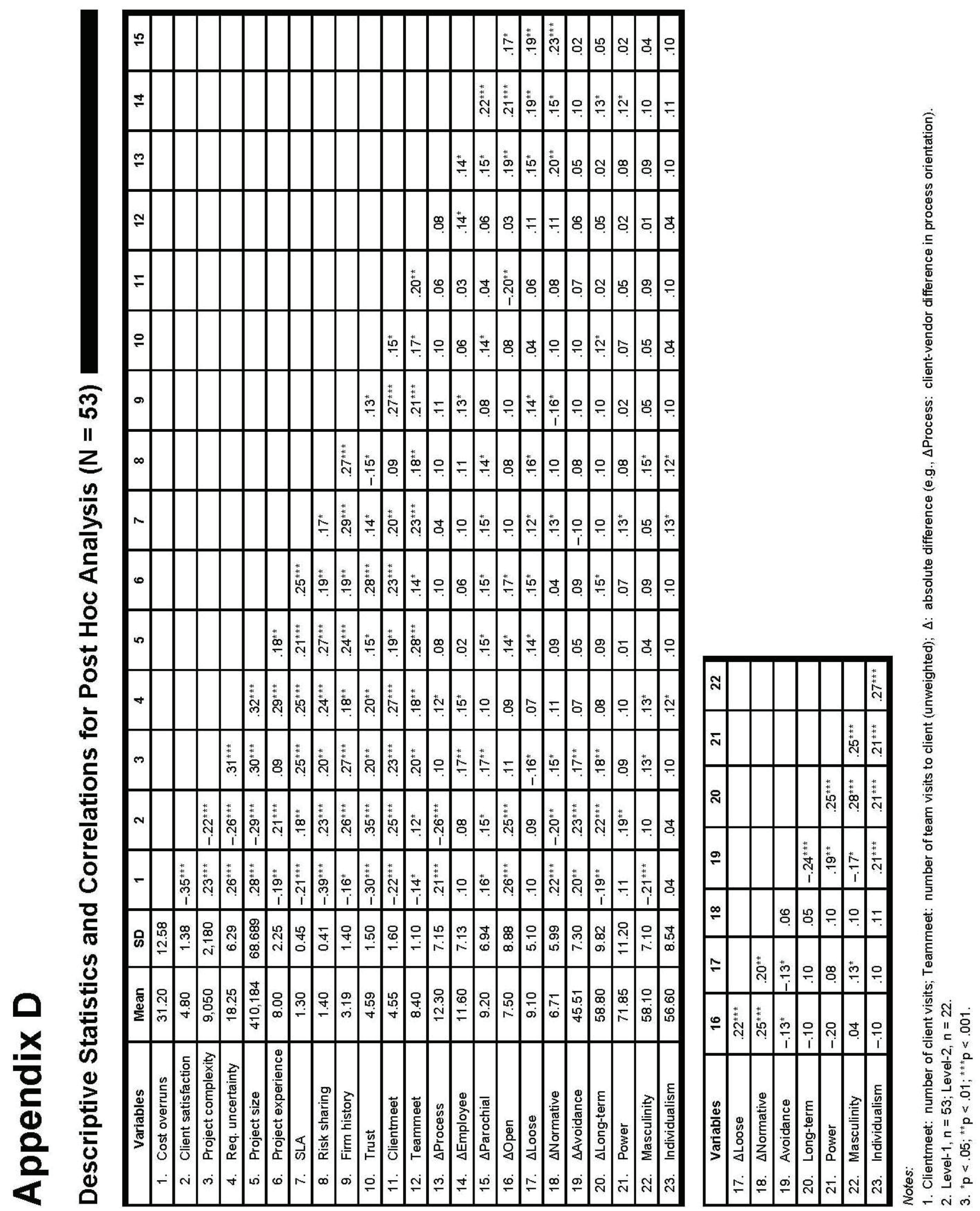